\title{
Photolysis of acetonitrile in a water-rich ice as a source of complex organic molecules: $\mathrm{CH}_{3} \mathrm{CN}$ and $\mathrm{H}_{2} \mathrm{O}: \mathrm{CH}_{3} \mathrm{CN}$ ices
}

\author{
M. Bulak ${ }^{1}$, D. M. Paardekooper ${ }^{1}$, G. Fedoseev ${ }^{1,2}$, and H. Linnartz ${ }^{1}$ \\ ${ }^{1}$ Laboratory for Astrophysics, Leiden Observatory, Leiden University, PO Box 9513, 2300 RA Leiden, The Netherlands \\ e-mail: bulak@strw.leidenuniv.nl \\ ${ }^{2}$ Research Laboratory for Astrochemistry, Ural Federal University, Kuibysheva St. 48, 620026 Ekaterinburg, Russia
}

Received 16 October 2020 / Accepted 8 January 2021

\begin{abstract}
Context. Many C-, O-, and H-containing complex organic molecules (COMs) have been observed in the interstellar medium (ISM) and their formation has been investigated in laboratory experiments. An increasing number of recent detections of large N-bearing COMs motivates our experimental investigation of their chemical origin.

Aims. We investigate the potential role of acetonitrile $\left(\mathrm{CH}_{3} \mathrm{CN}\right)$ as a parent molecule to N-bearing COMs, motivated by its omnipresence in the ISM and structural similarity to another well-known precursor species, $\mathrm{CH}_{3} \mathrm{OH}$. The aim of the present work is to characterize the chemical complexity that can result from vacuum UV photolysis of a pure $\mathrm{CH}_{3} \mathrm{CN}$ ice and a more realistic mixture of $\mathrm{H}_{2} \mathrm{O}: \mathrm{CH}_{3} \mathrm{CN}$.

Methods. The $\mathrm{CH}_{3} \mathrm{CN}$ ice and $\mathrm{H}_{2} \mathrm{O}: \mathrm{CH}_{3} \mathrm{CN}$ ice mixtures were $\mathrm{UV}$ irradiated at $20 \mathrm{~K}$. Laser desorption post ionization time-of-flight mass spectrometry was used to detect the newly formed COMs in situ. We examined the role of water in the chemistry of interstellar ices through an analysis of two different ratios of $\mathrm{H}_{2} \mathrm{O}: \mathrm{CH}_{3} \mathrm{CN}$ (1:1 and 20:1).

Results. We find that $\mathrm{CH}_{3} \mathrm{CN}$ is an excellent precursor to the formation of larger nitrogen-containing $\mathrm{COMs}$, including $\mathrm{CH}_{3} \mathrm{CH}_{2} \mathrm{CN}_{\text {, }}$ $\mathrm{NCCN} / \mathrm{CNCN}$, and $\mathrm{NCCH}_{2} \mathrm{CH}_{2} \mathrm{CN}$. During the UV photolysis of $\mathrm{H}_{2} \mathrm{O}: \mathrm{CH}_{3} \mathrm{CN}$ ice, the water derivatives play a key role in the formation of molecules with functional groups of: imines, amines, amides, large nitriles, carboxylic acids, and alcohols. We discuss possible formation pathways for molecules recently detected in the ISM.
\end{abstract}

Key words. astrochemistry - molecular processes - methods: laboratory: solid state - circumstellar matter - ISM: molecules ultraviolet: ISM

\section{Introduction}

Astronomical detections of over 200 different molecules demonstrate the chemical diversity of the interstellar medium (ISM). Alongside many smaller species, typically di- and triatomics, a large amount of $\mathrm{C}-, \mathrm{O}-, \mathrm{N}-$, and $\mathrm{H}$-bearing species have been identified that contain six or more atoms. From an astrochemical perspective, these species are considered complex organic molecules (COMs) and make up 25 percent of the detected molecules (van Dishoeck 2014; McGuire 2018). Of particular interest are 'prebiotic' species, a molecular subgroup that is relevant in the formation of amino acids or other molecules important for emergence of life. Nitriles are often considered as prebiotic molecules due to their ability to produce amides and carboxylic acids (including amino acids) upon hydrolysis in aqueous solutions. Acetonitrile $\left(\mathrm{CH}_{3} \mathrm{CN}\right)$ is a part of this family as the simplest of the alkyl nitriles (Bernstein et al. 2002; Hudson et al. 2008).

$\mathrm{CH}_{3} \mathrm{CN}$ is a symmetric top molecule with a large dipole moment of $3.92 \mathrm{D}$. In the gas phase, it has been detected through its strong millimeter transitions. $\mathrm{CH}_{3} \mathrm{CN}$ has been observed both in our Solar System and beyond (Cordiner et al. 2015; Goesmann et al. 2015; Woodney et al. 2002; Solomon et al. 1971; Öberg et al. 2015; Bergner et al. 2018; Purcell et al. 2006; Calcutt et al. 2018). Whereas identifications so far are limited to the gas phase, it is generally assumed that $\mathrm{CH}_{3} \mathrm{CN}$ is present on icy dust grains and plays an important role in solid state nitrogen chemistry (e.g., Loomis et al. 2013). Recently, $\mathrm{CH}_{3} \mathrm{CN}$ was identified towards the circumstellar disk around V883 Ori (Lee et al. 2019), where its origin as well as that of several other COMs methanol, acetone, acetaldehyde, and methyl formate - was directly linked to species sputtered from icy dust grains. These observations are in line with the idea that COMs form on icy dust grains through surface reactions that are triggered by impacting atoms, upon UV irradiation, electron bombardment, cosmic ray interactions, or through thermal processing. In recent years, many efforts have been taken to study such processes under fully controlled laboratory conditions. The results are then linked to astronomical observations or used as physical chemical input for astrochemical models. (e.g., Garrod \& Herbst 2006; Garrod et al. 2008; Walsh et al. 2014).

The majority of the identified COMs have been detected toward high-mass hot cores. Specific detections of nitriles and other nitrogen bearing species, including that of astrobiological importance, are: hydrogen cyanide $(\mathrm{HCN})$, isocyanic acid ( $\mathrm{HNCO})$, formamide $\left(\mathrm{NH}_{2} \mathrm{CHO}\right)$, methylamine $\left(\mathrm{CH}_{3} \mathrm{NH}_{2}\right)$, methyl isocyanate $\left(\mathrm{CH}_{3} \mathrm{NCO}\right)$, amino acetonitrile $\left(\mathrm{NH}_{2} \mathrm{CH}_{2} \mathrm{CN}\right)$, ethyl cyanide $\left(\mathrm{CH}_{3} \mathrm{CH}_{2} \mathrm{CN}\right)$, vinyl cyanide $\left(\mathrm{CH}_{2} \mathrm{CHCN}\right)$, cyanoacetylene $(\mathrm{HCCCN})$, acetamide $\left(\mathrm{CH}_{3} \mathrm{CONH}_{2}\right)$, (tentatively) $\mathrm{N}$-methyl formamide $\left(\mathrm{CH}_{3} \mathrm{NHCHO}\right)$, urea $\left(\mathrm{NH}_{2} \mathrm{CONH}_{2}\right)$, and, more recently, glycolonitrile $\left(\mathrm{HOCH}_{2} \mathrm{CN}\right)$ and propargylimine (HCCCHNH); (Snyder \& Bhul 1971; Bisschop et al. 2007; Fourikis et al. 1974; Halfen et al. 2015; Ligterink et al. 2017; Belloche et al. 2008, 2017, 2019; Calcutt et al. 2018; Hollis et al. 2006; Zeng et al. 2019; Bizzocchi et al. 2020). 
In light of these detections and their prebiotic relevance, abundant nitrogen bearing species, such as $\mathrm{HCN}$ $\left(\mathrm{HCN} / \mathrm{CH}_{3} \mathrm{CN} \approx 100\right)$, have been previously investigated as a precursor of N-bearing COMs (Liszt et al. 2018; Gerakines et al. 2004). Energetic processing of $\mathrm{H}_{2} \mathrm{O}: \mathrm{HCN}$ mixtures resulted in formation of $\mathrm{HNCO}, \mathrm{NH}_{4}{ }^{+} \mathrm{OCN}^{-}$, and $\mathrm{HCONH}_{2}$, which shows the potential of acetonitrile in the formation of N-bearing COMs, however, it does not conclusively prove the formation of many of the astronomically detected imines, amines, other amides, and large (iso)nitriles. Other previously studied potential precursors of N-bearing molecules include: $\mathrm{HNCO}, \mathrm{NH}_{3}, \mathrm{~N}_{2}, \mathrm{NO}$ (Ligterink et al. 2018, 2017; Jones et al. 2011; Raunier et al. 2004; Islam et al. 2014; Fedoseev et al. 2016; Ioppolo et al. 2014). These investigations successfully demonstrated formation routes for particular species such as: $\mathrm{NH}+\mathrm{CO} \rightarrow \mathrm{HNCO}, \mathrm{NO}+\mathrm{H} \rightarrow$ $\mathrm{NH}_{2} \mathrm{OH}, \quad \mathrm{NH}_{2}+\mathrm{CHO} \rightarrow \mathrm{NH}_{2} \mathrm{CHO}$, or $\mathrm{CH}_{3}+\mathrm{NH}_{2} \mathrm{CO} \rightarrow$ $\mathrm{CH}_{3} \mathrm{CONH}_{2}$. These contribute to our understanding of the chemical network for N-bearing COMs, that, however, remains incomplete, given the astronomically identified species. These studies suggest that perhaps a larger molecule, also ubiquitous in the ISM but less abundant than $\mathrm{HCN}$, like $\mathrm{CH}_{3} \mathrm{CN}$, is a more fitting candidate for a precursor of $\mathrm{N}$-bearing COMs.

In comparison, many $\mathrm{C}-, \mathrm{O}-$, and $\mathrm{H}$-bearing $\mathrm{COMs}$ have been linked to UV irradiated $\mathrm{CH}_{3} \mathrm{OH}$ ices (Öberg et al. 2009; Paardekooper et al. 2016a). The molecular structure of acetonitrile $\left(\mathrm{CH}_{3}-\mathrm{CN}\right)$ somehow resembles that of methanol $\left(\mathrm{CH}_{3}-\right.$ $\mathrm{OH})$. Both molecules have several accessible photodissociation pathways which result in formation of radicals: $\mathrm{CH}_{3}+\mathrm{OH}$, $\mathrm{CH}_{3} \mathrm{O}+\mathrm{H}, \mathrm{CH}_{2} \mathrm{OH}+\mathrm{H}$ for $\mathrm{CH}_{3} \mathrm{OH}$ and $\mathrm{CH}_{3}+\mathrm{CN}, \mathrm{CH}_{2} \mathrm{CN}+\mathrm{H}$ for $\mathrm{CH}_{3} \mathrm{CN}$. The variety of radicals available in the ice indicates the potential of a precursor to increase the chemical complexity in the ice. $\mathrm{CH}_{3} \mathrm{CN}$ - even though detected at abundances of a few percent of $\mathrm{CH}_{3} \mathrm{OH}$ around protostars and comets (Mumma \& Charnley 2011; Bergner et al. 2017) can be regarded as a promising parent molecule to yield its own branch of COM derivatives, whereas the formation of methanol through $\mathrm{CO}$ hydrogenation is well-known (Watanabe et al. 2003; Fuchs et al. 2009; Linnartz et al. 2015), the interstellar formation pathways of $\mathrm{CH}_{3} \mathrm{CN}$ are less known. In fact, both gas phase and solid state routes have been proposed. In the gas phase formation may proceed through radiative association:

$\mathrm{HCN}+\mathrm{CH}_{3}^{+} \rightarrow \mathrm{C}_{2} \mathrm{H}_{4} \mathrm{~N}^{+}+$photon

and followed by dissociative recombination:

$\mathrm{C}_{2} \mathrm{H}_{4} \mathrm{~N}^{+}+\mathrm{e}^{-} \rightarrow \mathrm{CH}_{3} \mathrm{CN}+\mathrm{H}$,

as proposed by Mackay (1999); Willacy et al. (1993); Vigren et al. (2008). In the solid state, the formation of $\mathrm{CH}_{3} \mathrm{CN}$ is possible through the hydrogenation of $\mathrm{C}_{2} \mathrm{~N}$ (Belloche et al. 2009) or radical recombination $\mathrm{CH}_{3}+\mathrm{CN}$ (Garrod et al. 2008). In fact, the latter scenario would place the formation of $\mathrm{CH}_{3} \mathrm{CN}$ in a water-rich phase of the ice, due to the involvement of the methyl radical, $\mathrm{CH}_{3}$ (Qasim et al. 2020). Recent observational work by Loomis et al. (2018) indicates that the molecular origin of $\mathrm{CH}_{3} \mathrm{CN}$ in the protoplanetary disk TW Hya is dominated by solid state pathways, in line with the already mentioned study by Lee et al.

The first studies using $\mathrm{CH}_{3} \mathrm{CN}$ as a starting point in the formation of larger COMs in solid state were reported by Hudson \& Moore (2004) and Abdulgalil et al. (2013). Upon UV irradiation of pure $\mathrm{CH}_{3} \mathrm{CN}$ ice, the following products were identified: $\mathrm{HCN}, \mathrm{CH}_{4}$, and $\left(\mathrm{CH}_{2} \mathrm{CN}\right)_{2}$. It was also found that the parent species isomerizes to $\mathrm{CH}_{3} \mathrm{NC}$ and $\mathrm{H}_{2} \mathrm{CCNH}$. In these experiments, the photoproducts were identified using infrared (IR) spectroscopy, an in situ analytical technique. The limitations of the technique become apparent for overlapping infrared signatures of molecules in the ice as well as for photoproducts formed at low abundances. The lowest photoproduct column density detected in Hudson \& Moore (2004) is $4 \times 10^{15}$ molecules $\mathrm{cm}^{-2}$, which is approximately two orders of magnitude less sensitive than the detection threshold in this study (see Sect. 3.1).

In a follow-up investigation by Hudson et al. (2008), $\mathrm{H}_{2} \mathrm{O}: \mathrm{CH}_{3} \mathrm{CN}$ mixtures were analyzed using (ex situ) gas or liquid chromatography mass spectrometry (GC/LC-MS). In these experiments, the residue formed during an energetic processing of the ice mixture was heated to room temperature, exposed to air, dissolved, and evaporated in a GC-MS. The results demonstrated a rich reservoir of $\mathrm{N}$-bearing COMs, including amines, amides, and large nitriles. In addition, when the residue was acid-hydrolyzed, it yielded a variety of amino acids (Hudson et al. 2008). The prebiotic potential of $\mathrm{CH}_{3} \mathrm{CN}$ was confirmed in a study by Danger et al. (2011), in which a $\mathrm{CH}_{3} \mathrm{CN}: \mathrm{NH}_{3}$ mixture was demonstrated to yield amino acetonitrile. Hydrolysis of amino acetonitrile in liquid solution at room temperature is known to form glycine.

While UV photolysis of $\mathrm{CH}_{3} \mathrm{CN}$ ice was clearly shown to trigger solid state chemical processes, hydrogenation of $\mathrm{CH}_{3} \mathrm{CN}$ by thermalized $\mathrm{H}$ atoms was found to be rather inefficient due to a high energy barrier for the first $\mathrm{H}$ atom addition (Nguyen et al. 2019). Conversely, for the hydrogenation of isonitrile $\mathrm{CH}_{3} \mathrm{NC}$, the barrier was found to be lower, leading to the formation of secondary amines $\left(\mathrm{CH}_{3} \mathrm{NHCH}_{3}\right)$. Other chemical routes may also be relevant in the formation of $\mathrm{N}$-bearing prebiotics.

In the present work, we focus on UV-induced reactions in pure $\mathrm{CH}_{3} \mathrm{CN}$ ice and $\mathrm{H}_{2} \mathrm{O}: \mathrm{CH}_{3} \mathrm{CN}$ ice mixtures. The aim of the analysis is to demonstrate the formation of heavier COMs. This becomes possible through application of a new ultra-sensitive detection method based on laser desorption post ionization time-of-flight mass spectrometry (Paardekooper et al. 2014). The details are described in Sect. 2. Our primary goal is to improve our understanding of solid state astrochemical reactions that extend existing networks resulting in the formation of (N-bearing) COMs. The results are presented and discussed in Sect. 3. Information on the underlying reaction network showing how imines, amines, amides, and nitriles chemically connect and the "catalytic" role of water are presented. In Sect. 4, the astrophysical relevance is discussed and the manuscript concludes with a summary of all findings in Sect. 5.

\section{Experimental}

The experiments were performed using an ultra-high vacuum (UHV) system called MATRI ${ }^{2}$ CES (Mass Analysis Tool to study Reactions in Interstellar ICES). This section provides the relevant information, however, a detailed description of MATRI $^{2}$ CES can be found in Paardekooper et al. (2014). In the following section, we discuss experimental procedures as well as an overview of the experiments performed are discussed.

\subsection{Setup and analysis tools}

MATRI ${ }^{2}$ CES is a two chamber system, with a base pressure in the $10^{-10}$ mbar range. The main chamber houses a closed-cycle Helium cryostat which cools a $2.5 \mathrm{~cm} \times 5 \mathrm{~cm}$ large gold-coated copper substrate to a temperature of $20 \mathrm{~K}$. A thermocouple and a resistive heater are attached to the cold finger, allowing a Lakeshore 331 temperature controller to regulate the temperature 
of the substrate between 20 and $300 \mathrm{~K}$ with a roughly $1 \mathrm{~K}$ precision. Ice growth on the substrate proceeds via needle valves that guarantee a continuous and stable deposition pressure in the main chamber. The needle valve on the front is connected to a tube which faces the sample at an angle of 85 degrees with respect to the substrate. Acetonitrile $\left(\mathrm{CH}_{3} \mathrm{CN}\right.$, VWR, $<10 \mathrm{ppm}$ of water), and acetonitrile-D3 $\left(\mathrm{CD}_{3} \mathrm{CN}\right.$, SigmaAldrich, $\geq 99.8 \% \mathrm{D})$ are used. In order to simultaneously admit water vapor $\left(\mathrm{H}_{2} \mathrm{O}\right.$, miliQ or $\mathrm{H}_{2}{ }^{18} \mathrm{O}$, Sigma-Aldrich, $\left.97 \%{ }^{18} \mathrm{O}\right)$, an additional needle valve located behind the substrate is used. Prior to deposition, atmospheric gases trapped in the samples are removed by several freeze-pump-thaw cycles. The growth rates are determined in advance by HeNe interference measurements as discussed in previous works (Baratta \& Palumbo 1998; Bulak et al. 2020).

UV irradiation of the ice is accomplished with a microwave discharge hydrogen flowing lamp (MDHL, F-type), which is connected to the main chamber by a magnesium fluoride $\left(\mathrm{MgF}_{2}\right)$ viewport and directly faces the substrate. The lamp produces vacuum UV photons with energies in the 7-10.2 eV range and simulates interstellar radiation field (ISRF). Throughout all experiments, the lamp is run at a $\mathrm{H}_{2}$ pressure of 1.4 mbar and $80 \mathrm{~W}$ of microwave power. The corresponding SED contains both Lyman- $\alpha(121.6 \mathrm{~nm})$ and molecular $\mathrm{H}_{2}$ emission continuum (130-165 nm); the full SED is given in Fig. 4 in Paardekooper et al. (2016b). The impacting radiation causes various processes in the ice molecules, for example, excitation, dissociation, desorption, or even ionization in the case if ionization threshold is below the energy of the present UV photons. For an overview of photo-induced processes, see Fig. 1 in Bulak et al. (2020). The photon flux of the MDHL is measured at the location of the substrate with a NIST calibrated photodiode and found to be $(2.5 \pm 0.5) \times 10^{14}$ photons $\mathrm{cm}^{-2} \mathrm{~s}^{-1}$.

As analytical technique, laser desorption post ionization time-of-flight mass spectrometry (LDPI TOF-MS) is applied to probe the composition of the ice at different vacuum UV fluences. The light of an unfocused $(\sim 1 \mathrm{~mm}) \mathrm{Nd}$ :YAG laser beam (355 $\mathrm{nm}$ and $4-5 \mathrm{~ns}$ pulse length) is used as an ice ablation source. Typical laser pulse energies of $65 \mathrm{~mJ} \mathrm{~cm} \mathrm{~cm}^{-2}$ are applied. Ice species that are desorbed are subsequently ionized in the gas phase using $70 \mathrm{eV}$ electrons and guided by ion optics located in front of the substrate into the second chamber, which contains a field-free time of flight mass spectrometry (TOF-MS) system. The latter is operated in reflectron mode to increase mass resolution $(\Delta m / m \sim 250)$. In order to select different parts of the photoprocessed ice for sequential laser ablation steps, the position of the cryostat (and substrate) can be moved using a two-dimensional translation stage. In the vertical direction, translation is driven by a stepper motor, and in the horizontal direction, it is manually controlled. The motorized vertical translational stage allows for synchronization with laser shots, resulting in each shot probing a fresh location on the ice, while ensuring that the location of the desorption plume with respect to the ion optics remains the same. This approach results in minimal shot-to-shot fluctuations, while ensuring that multiple averages can be used to increase the overall signal-to-noise ratio. Every mass spectrum presented in this study is based on 100 averages obtained at different locations on the ice coated substrate. To trace the changes in the chemical composition of the ice, raw TOF spectra are collected at different photon fluences. In order to determine the elemental compositions of the new signals in the mass spectra, each experiment is performed for two isotopes. For the pure ice, $\mathrm{CH}_{3} \mathrm{CN}$ and $\mathrm{CD}_{3} \mathrm{CN}$, and for the mixed ices, $\mathrm{CH}_{3} \mathrm{CN}: \mathrm{H}_{2}{ }^{16} \mathrm{O}$ and $\mathrm{CH}_{3} \mathrm{CN}: \mathrm{H}_{2}{ }^{18} \mathrm{O}$, are used.
The dominating process driving the reactions in the ice is photodissociation followed by radical-radical and radicalmolecule interactions. Hence, the combination of elemental composition of the new ions, with fragmentation patterns of the expected products from the NIST database, allows us to tentatively identify the newly formed photoproducts. In addition, based on the order of appearance of the new mass peaks, assigned species can be roughly separated into first and second generation photoproducts.

Quantitatively, the mass spectra are analysed by calculating the integrated area of each peak by fitting a Pearson IV distribution (Castellanos et al. 2018). This function allows for peak asymmetry and, therefore, it is able to accurately fit the individual peaks. The errors related to the integration are estimated by calculating the root mean square (rms) over the residual (difference between experimental data and fit) within one standard deviation from the center. It is noted that these errors only represent the fitting procedure and other experimental uncertainties may be present. The resulting intensities of mass peaks can be regarded as a linear combination of multiple individual compounds present in the plume (Paardekooper et al. 2014). Hence, an integrated mass spectrum, $M_{t}$, at a given irradiation time, $t$, can be expressed by:

$M_{t}=\sum_{i=1}^{n} a_{i} \cdot \sigma_{i} \cdot M_{i}$,

where $a_{i}$ is the molecular abundance of species $i, \sigma_{i}$ is the ionization cross section, and $M_{\mathrm{i}}$ is the corresponding fragmentation pattern. To derive product abundances, we fit our experimental data using a limited memory Broyden-FletcherGoldfarb-Shanno (L-BFGS) optimisation algorithm incorporated in Python. This allows to take into account all parameters from Eq. (3) and trace the evolution of different species in the ice throughout the UV photoprocessing. Where available, NIST mass spectra are used as input for the reference mass spectra.

\subsection{Overview experiments}

Table 1 summarizes all the relevant experiments included in this study. The experiments allow to get an insight into the early stages of the photolysis process. At a low photon fluence, the radical concentration in the ice is low, hence, the impact of the second order reactivity, including reversed reactions, is limited. The experiments performed at temperature of $20 \mathrm{~K}$, are extended to be representative for a lifetime of a dense molecular cloud, which may experience a total fluence as high as (3-30) $\times$ $10^{17}$ photons $\mathrm{cm}^{-2}$. This value has been estimated using a cosmic ray-induced UV flux of $(1-10) \times 10^{3}$ photons $\mathrm{cm}^{-2} \mathrm{~s}^{-1}$ and an average molecular cloud lifetime of up to $10^{7} \mathrm{yr}$ (Shen et al. 2004). The $\mathrm{CH}_{3} \mathrm{CN}$ and complimentary $\mathrm{CD}_{3} \mathrm{CN}$ experiments are conducted to confirm product assignments. The same approach is used for two different $\mathrm{H}_{2} \mathrm{O}: \mathrm{CH}_{3} \mathrm{CN}$ ice mixtures.

A complementary diagnostic tool for the identification of photoproducts can be realized by taking into account the characteristic desorption temperatures (Paardekooper et al. 2016a). For this, a pure $\mathrm{CH}_{3} \mathrm{CN}$ ice is UV-irradiated at $20 \mathrm{~K}$ and then slowly warmed up, applying LDPI TOF-MS at selected higher temperatures in the range from 20 to $285 \mathrm{~K}$. The intensity difference for spectra recorded above and below a typical desorption temperature should yield a negative value at the characteristic $\mathrm{m} / \mathrm{z}$ peaks for the newly formed product.

The blank experiment was performed to demonstrate that all detected reaction products form in the deposited ice, rather than 


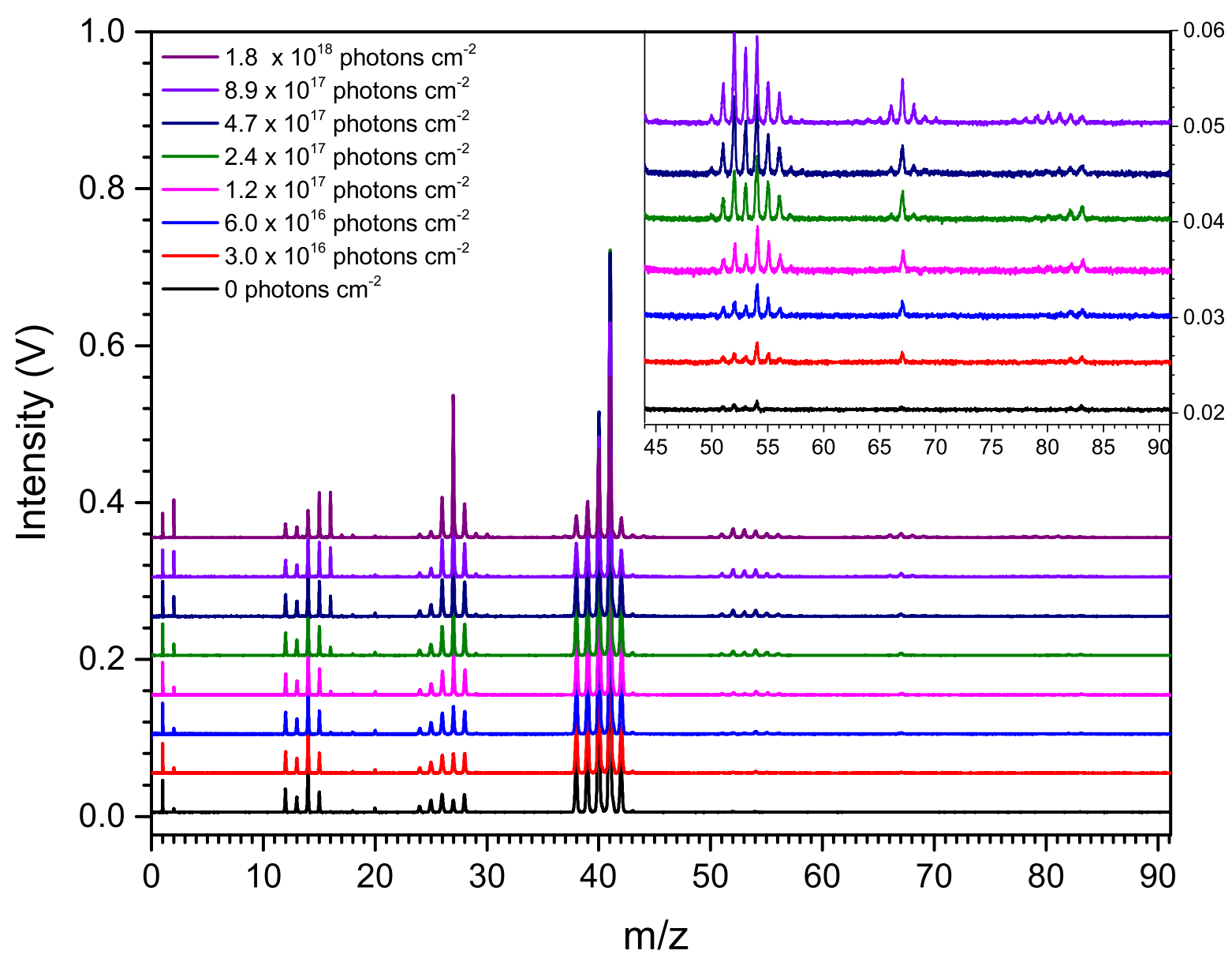

Fig. 1. LDPI TOF-MS signals for an UV irradiated $\mathrm{CH}_{3} \mathrm{CN}$ ice at $20 \mathrm{~K}$ for increasing photon fluence. The lowest graph shows the signal without UV irradiation. The inset is a zoom on the intensity scale for the higher masses.

Table 1. Summary of the performed $\mathrm{CH}_{3} \mathrm{CN}$ and $\mathrm{H}_{2} \mathrm{O}: \mathrm{CH}_{3} \mathrm{CN} \mathrm{UV}$ photolysis experiments.

\begin{tabular}{cccc}
\hline \hline Composition & $\begin{array}{c}\text { Thickness } \\
(\mathrm{ML})\end{array}$ & $\begin{array}{c}\text { Temperature } \\
(\mathrm{K})\end{array}$ & $\begin{array}{c}\text { UV irradiation } \\
(\mathrm{min})\end{array}$ \\
\hline $\mathrm{CH}_{3} \mathrm{CN}$ & 40 & 20 & $0-128$ \\
$\mathrm{CH}_{3} \mathrm{CN}$ & 40 & $20-285$ & $0-128$ \\
$\mathrm{CD}_{3} \mathrm{CN}$ & 40 & 20 & $0-128$ \\
$\mathrm{H}_{2} \mathrm{O}: \mathrm{CH}_{3} \mathrm{CN}$ & & & \\
$(\sim 1: 1)$ & 100 & 20 & $0-128$ \\
$\mathrm{H}_{2} \mathrm{O}: \mathrm{CH}_{3} \mathrm{CN}$ & & & \\
$(\sim 20: 1)$ & 100 & 20 & $0-128$ \\
$\mathrm{H}_{2}{ }^{18} \mathrm{O}: \mathrm{CH}_{3} \mathrm{CN}$ & & & \\
$(\sim 20: 1)$ & 100 & 20 & $0-128$ \\
blank & 0 & $20,160-300$ & 60 \\
\hline
\end{tabular}

Notes. The UV irradiation time is given in minutes, with a photon flux of $(1.5 \pm 0.5) \times 10^{16}$ photons $\mathrm{cm}^{-2} \mathrm{~min}^{-1}$. All experiments were run more than once.

externally, that is, forming on the walls of the setup or in the ion optics. To test this, the cold substrate $(20 \mathrm{~K})$ is UV-irradiated and probed via LDPI TOF-MS. This procedure is also performed at higher temperatures, following the deposition of $\mathrm{CH}_{3} \mathrm{CN}$ above its thermal desorption threshold (160-300 K). In all experiments, the dominant uncertainty source follows the absolute calibration of the deposition rate and UV flux. The error bars shown in the kinetics diagrams (Fig. 4) are a result of the fitting routine of the particular mass peaks.

\section{Results and discussion}

This section comprises of three parts. First, we discuss the photolysis of pure $\mathrm{CH}_{3} \mathrm{CN}$ ice. Then the LDPI TOF-MS data are presented and photoproducts are assigned. The production yields of first-generation photoproducts are calculated. Second, a similar qualitative analysis is done for the UV photolysis of $\mathrm{H}_{2} \mathrm{O}: \mathrm{CH}_{3} \mathrm{CN}$ ice mixtures. The photoproduct assignments are additionally supported by mass spectra from experiments for two different mixing ratios (1:1 and 20:1). In the third part, the chemical role of water molecules is presented.

\section{1. $\mathrm{CH}_{3} \mathrm{CN}$ photoproducts}

Mass spectra obtained throughout the UV photolysis of pure $\mathrm{CH}_{3} \mathrm{CN}$ ice are shown in Fig. 1. The bottom trace shows the signature of an unprocessed acetonitrile ice with a characteristic fragmentation pattern spread over multiple mass peaks $(\mathrm{m} / \mathrm{z}=$ $12-15,24-28,38-42)$. It serves as a reference for tracking any changes in the chemical composition of the ice. After two minutes of UV irradiation $\left(3.0 \times 10^{16}\right.$ photons $\mathrm{cm}^{-2}$, represented by the red trace), new peaks arise at $\mathrm{m} / \mathrm{z}$ values: $16,27-29$, 51-56, 67, 82, 83. As photolysis proceeds (see the remaining traces), additional peaks appear in the spectra, demonstrating a rapid increase in the total number of species newly formed in 
Table 2. Characteristic m/z peaks used for identification of photoproducts of UV photolysis of $\mathrm{CH}_{3} \mathrm{CN}$ ice.

\begin{tabular}{|c|c|c|c|c|}
\hline $\begin{array}{c}\mathrm{CH}_{3} \mathrm{CN} \\
\mathrm{m} / \mathrm{z}\end{array}$ & $\begin{array}{c}\mathrm{CD}_{3} \mathrm{CN} \\
m / z\end{array}$ & $\begin{array}{c}\text { Elemental } \\
\text { composition }\end{array}$ & $\begin{array}{c}\text { Proposed } \\
\text { molecular species }\end{array}$ & Name \\
\hline 2 & 4 & $\mathrm{H}_{2}$ & $\mathrm{H}_{2}$ & Mol. hydrogen \\
\hline$[0.5 \mathrm{pt}] 16$ & 20 & $\mathrm{CH}_{4}$ & $\mathrm{CH}_{4}$ & Methane $(*)$ \\
\hline 26,27 & 26,28 & $\mathrm{CNH}$ & $\mathrm{HCN} / \mathrm{HNC}$ & Hydrogen (iso)cyanide $(*)$ \\
\hline 40,41 & 42,44 & $\mathrm{C}_{2} \mathrm{NH}_{3}$ & $\begin{array}{c}\mathrm{CH}_{3} \mathrm{CN} / \mathrm{CH}_{3} \mathrm{NC} / \\
\mathrm{H}_{2} \mathrm{CCNH}\end{array}$ & $\begin{array}{c}\text { Acetonitrile/methyl isocyanide }(*) / \\
\text { Ketenimine }(*)\end{array}$ \\
\hline 50,51 & 50,52 & $\mathrm{C}_{3} \mathrm{NH}$ & $\mathrm{HCCCN}$ & Propiolonitrile $(*)$ \\
\hline 52 & 52 & $\mathrm{C}_{2} \mathrm{~N}_{2}$ & $(\mathrm{CN})_{2}$ & Cyanogen \\
\hline $26,52,53$ & $26,54,56$ & $\mathrm{C}_{3} \mathrm{NH}_{3}$ & $\mathrm{CH}_{2} \mathrm{CHCN}$ & 2-propenenitrile \\
\hline 28,54 & 30,58 & $\mathrm{C}_{3} \mathrm{NH}_{5}$ & $\mathrm{CH}_{3} \mathrm{CH}_{2} \mathrm{CN}$ & Propanenitrile \\
\hline 29,55 & 32,60 & $\mathrm{C}_{3} \mathrm{NH}_{5}$ & $\mathrm{CH}_{3} \mathrm{CH}_{2} \mathrm{NC}$ & Ethyl isocyanide \\
\hline 56 & 62 & $\mathrm{C}_{3} \mathrm{NH}_{6}$ & - & Imine (R-CHNH) \\
\hline $65-69$ & $66,68,70,72,74$ & $\mathrm{C}_{3} \mathrm{~N}_{2} \mathrm{H}_{\mathrm{x}}$ & - & \\
\hline $77-83$ & $78-90$ & $\mathrm{C}_{4} \mathrm{~N}_{2} \mathrm{H}_{\mathrm{y}}$ & - & - \\
\hline
\end{tabular}

Notes. Species previously detected during in situ energetic processing of $\mathrm{CH}_{3} \mathrm{CN}$ ice are marked with an asterisk (*) based on Hudson \& Moore (2004); Abdulgalil et al. (2013).

the ice. The (inset in the) figure also shows the high detection sensitivity of MATRI ${ }^{2} \mathrm{CES}$ and its capability to quickly monitor the formation of larger COMs, up to at least six to seven $\mathrm{C} / \mathrm{N}$ atom-containing species $(\mathrm{m} / \mathrm{z}=93)$.

The assignment of the new peaks to specific molecules is not straight forward as the peaks merely reflect fragment masses due to the dissociative ionization method (electron impact ionization): upon dissociation different species may form identical fragments. Also, it is not a priori clear which species are expected to form as different processes are involved. Radicals created via photodissociation recombine with each other to form larger stable products. The MDHL produces photons in the energy range between $7-10.2 \mathrm{eV}$, which is below the ionization potential of the $\mathrm{CH}_{3} \mathrm{CN}$, but is sufficient to overcome a barrier for two photodissociation pathways: $\mathrm{CH}_{2} \mathrm{CN}-\mathrm{H}$ and $\mathrm{CH}_{3}-\mathrm{CN}$ with thresholds of 4 and $5.2 \mathrm{eV}$, respectively (Darwent 1970). Moreover, the formed CN radicals can be in electronically excited states (Kanda et al. 1999; Schwell et al. 2008). Given their high reactivity, the radicals do not build up an abundance sufficient to be detected directly. Instead, the stable end products of radical recombination can be studied. The radicals can also react with the abundantly present precursor species $\left(\mathrm{CH}_{3} \mathrm{CN}\right)$, for example, by interacting with the triple $\mathrm{C} \equiv \mathrm{N}$ bond. Alternatively, it is possible that newly formed species (e.g., $\mathrm{CH}_{3} \mathrm{CH}_{2} \mathrm{CN}$ ) can engage in a neutral-radical reactions or be photodissociated to supply a new, large radical for further reactions, as discussed in detail by Fedoseev et al. (2017). It is also possible that the resulting radicals participate in $\mathrm{H}$-atom abstraction reactions (Chuang et al. 2016).

An assignment of the mass peaks shown in Fig. 1 to specific species starts with the determination of the elemental composition of the new mass peaks. The observed mass peaks reflect either the ionized (and unfragmented) species formed along one of the three processes described above or one of the corresponding photoproduct fragments formed upon dissociative ionization. In addition, $\mathrm{CD}_{3} \mathrm{CN}$ is used as an isotopically enriched precursor to discriminate between mass peaks shifted because of hydrogen and deuterium contributions. Special care is taken that the overlap between the chosen characteristic peaks is minimum. In this way it is possible to link the majority of the observed mass peaks to an elemental $\mathrm{C} / \mathrm{N} / \mathrm{H}$ composition and this allows to conclude on the formation of several of the formed products, as will be illustrated later. Table 2 gives a summary of the observed mass peaks used to derive the elemental product composition and (tentative) assignments of species, newly formed upon UV photolysis of pure acetonitrile ice.

In Table 2 photoproducts formed as a result of isomerization are included, but their identification (and presence in the ice) cannot be confirmed using TOF mass spectrometry. Here, tandem mass spectrometry or spectroscopic methods would offer a possible alternative. This applies to most nitriles being restructured into isonitriles (e.g., $\mathrm{CH}_{3} \mathrm{CN} \rightarrow \mathrm{CH}_{3} \mathrm{NC}$ ) and acetonitrile isomerizing into ketenimine $\left(\mathrm{CH}_{3} \mathrm{CN} \rightarrow \mathrm{H}_{2} \mathrm{C}=\mathrm{C}=\mathrm{NH}\right)$, which has been discussed by Hudson \& Moore (2004).

To demonstrate the approach to photoproduct assignments, Fig. 2 highlights the isotopic shift between the $\mathrm{CH}_{3} \mathrm{CN}$ and $\mathrm{CD}_{3} \mathrm{CN}$ experiments. Following UV irradiation, an immediate increase in signals at $m / z=16$ and 27 is observed for $\mathrm{CH}_{3} \mathrm{CN}$ (red trace), which corresponds to an increase at $\mathrm{m} / z=20$ and $\mathrm{m} / \mathrm{z}=28$ when using the deuterated equivalent. The corresponding elemental compositions are $\mathrm{CH}_{4}$ and $\mathrm{HCN}$, which are obviously assigned to methane and hydrogen cyanide. Possible formation pathways of these species include hydrogenation of the $\mathrm{CN}$ and $\mathrm{CH}_{3}$ radicals, as demonstrated in previous studies (Borget et al. 2017; Qasim et al. 2020). For higher UV fluences (blue and pink traces), the abundance of these products continues to increase, while other peaks demonstrate further changes in the composition of the ice. Toward the end of $\mathrm{CH}_{3} \mathrm{CN}$ photolysis, peaks at $m / z=26,28,29$, and 30 increase. This mass range is characteristic for fragments of large (iso)nitrile species $\left(\mathrm{CH}_{3} \mathrm{CH}_{2} \mathrm{CN}, \mathrm{CH}_{2} \mathrm{CHCN}\right.$ and $\left.\mathrm{CH}_{3} \mathrm{CH}_{2} \mathrm{NC}\right)$. However, small species, if present in the ice (methanimine $\mathrm{CH}_{2} \mathrm{NH}$ ), might also contribute. Following the outcome of the deuterated experiments, these peaks can be matched with the following elemental compositions: $\mathrm{CN} / \mathrm{C}_{2} \mathrm{H}_{2}, \mathrm{CNH}_{2} / \mathrm{C}_{2} \mathrm{H}_{4}, \mathrm{CNH}_{3}$, and $\mathrm{CNH}_{4}$.

The higher $\mathrm{m} / \mathrm{z}$ range is analyzed using the same strategy, as shown in Fig. 3. Newly observed peaks are assigned to elemental compositions of $\mathrm{C}_{2} \mathrm{~N}_{2}, \mathrm{C}_{3} \mathrm{NH}_{x}, \mathrm{C}_{3} \mathrm{~N}_{2} \mathrm{H}_{x}$, and $\mathrm{C}_{4} \mathrm{~N}_{2} \mathrm{H}_{y}(x=1,3,5$ and $y=1,3,5,7)$. The mass peak at $\mathrm{m} / \mathrm{z}=52$, which is clearly visible in both experiments, is 


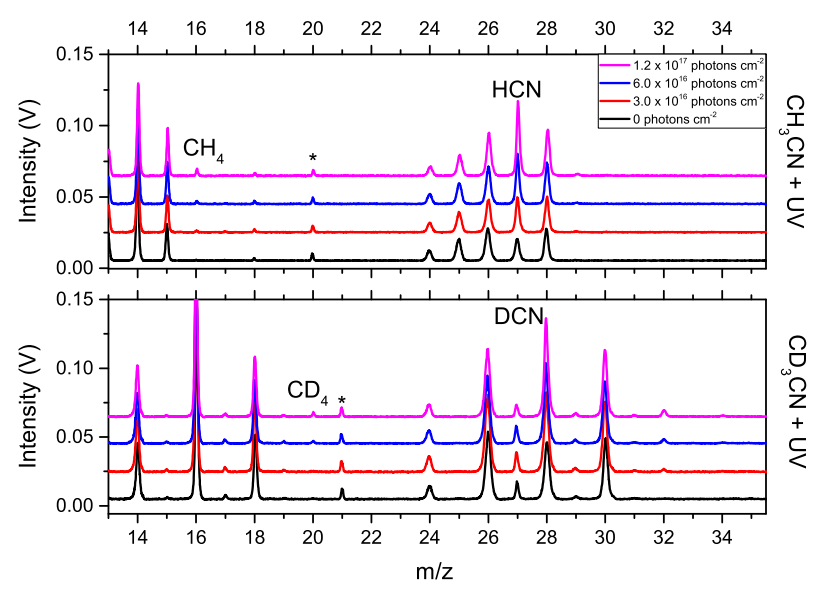

Fig. 2. Low $\mathrm{m} / z$ range of LDPI TOF-MS signals of pure $\mathrm{CH}_{3} \mathrm{CN}$ (top panel) and $\mathrm{CD}_{3} \mathrm{CN}$ (bottom panel) at $20 \mathrm{~K}$, as a function of photon fluence. Peak marked by an asterisk $(*)$ is a doubly ionized $\mathrm{CH}_{2} \mathrm{CN}^{2+}$.
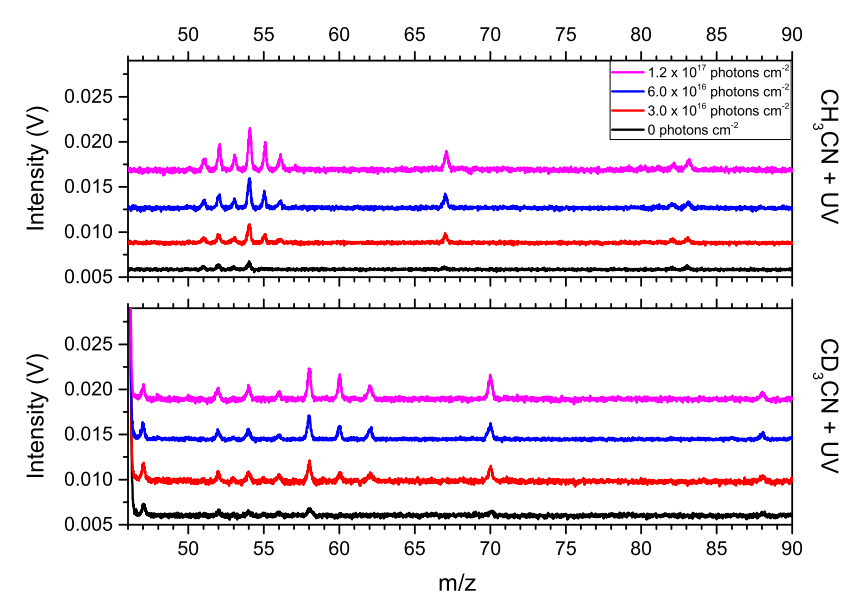

Fig. 3. High $\mathrm{m} / \mathrm{z}$, range of LDPI TOF-MS signals of pure $\mathrm{CH}_{3} \mathrm{CN}$ (top panel) and $\mathrm{CD}_{3} \mathrm{CN}$ (bottom panel) at $20 \mathrm{~K}$, as a function of photon fluence.

assigned to (iso)cyanogen (NCCN/CNCN). Based on characteristic mass peaks of (iso)nitriles with three carbon atoms (NIST Chemistry Webbook), the signals at 50-55 amu are assigned to a combination of propiolonitrile ( $\mathrm{HCCCN}$ ), acrylonitrile $\left(\mathrm{CH}_{2} \mathrm{CHCN}\right)$, propanenitrile $\left(\mathrm{CH}_{3} \mathrm{CH}_{2} \mathrm{CN}\right)$, and ethyl isocyanide $\left(\mathrm{CH}_{3} \mathrm{CH}_{2} \mathrm{NC}\right)$. The formation of NCCN/CNCN and $\mathrm{CH}_{3} \mathrm{CH}_{2} \mathrm{CN}$ is likely to proceed via radical recombination reactions. Peaks representing $\mathrm{CH}_{2} \mathrm{CHCN}$ and $\mathrm{HCCCN}$ appear later in the photolysis, which can be interpreted as a result of $\mathrm{UV}$-induced dehydrogenation of $\mathrm{CH}_{3} \mathrm{CH}_{2} \mathrm{CN}$.

The peak at $\mathrm{m} / \mathrm{z}=56$ shifts to $\mathrm{m} / \mathrm{z}=62$ in the deuterated experiments. This observation is consistent with a $\mathrm{C}_{3} \mathrm{NH}_{6}$ elemental composition which can only be obtained via the hydrogenation of $\mathrm{C} \equiv \mathrm{N}$ bond bond. This leads to imine formation, with a general structure of R-CHNH. As the involved fragmentation pattern is not known, it is unfortunately not possible to unambiguously confirm this assignment.

Mass peaks in the range of $\mathrm{m} / \mathrm{z}=65-69$ and $\mathrm{m} / \mathrm{z}=77-83$ have been assigned with elemental compositions $\mathrm{C}_{3} \mathrm{~N}_{2} \mathrm{H}_{x}(x=$ $1,3,5)$ and $\mathrm{C}_{4} \mathrm{~N}_{2} \mathrm{H}_{y}(y=1,3,5,7)$. Due to the visibility of traces at $m / z=67,82$, and 83 in the reference spectrum (before photolysis), and a significant increase of these signals during the experiments, it is likely that these represent newly formed large photolysis products. In this regard, it is important to exclude the notion that these peaks are a direct consequence of the used laser desorption method or originate from non-volatile residues from previous experiments.

It has been demonstrated that upon laser desorption, species with strong hydrogen bonds, such as $\mathrm{H}_{2} \mathrm{O}, \mathrm{CH}_{3} \mathrm{OH}$ or $\mathrm{CH}_{3} \mathrm{CN}$, form protonated clusters (e.g., $\left(\mathrm{H}_{2} \mathrm{O}\right)_{n} \mathrm{H}^{+}$, where $n=0,1,2$, and higher from Gudipati \& Yang 2012). Mass peaks of these clusters are easily recognized, as the corresponding peaks are evenly spaced and their intensities decrease with the size of the cluster $(n)$. Additionally, the intensity of the cluster peaks follows the abundance of the parent molecule. Hence, if $\mathrm{CH}_{3} \mathrm{CN}$ abundance decreases, any peaks assigned to $\left(\mathrm{CH}_{3} \mathrm{CN}\right)_{n} \mathrm{H}^{+}$(where $n=0,1,2$ ) should follow this trend (Ribeiro et al. 2020). This behaviour is not seen in our spectra (see Fig. 1). On the contrary, the peaks at $\mathrm{m} / z=65-69$ and $\mathrm{m} / \mathrm{z}=77-83$ increase, while the parent species decreases, hence, these peaks do not originate from clustering upon laser desorption. We performed blank experiments to exclude the role of any non-volatile residue on the substrate left over from previous experiments. At an increased laser power (doubled) and detector voltage (increased by $300 \mathrm{~V}$ ), some residue is detected. Subsequently, the substrate is irradiated for $1 \mathrm{~h}$ and new small mass peaks are observed in the mass spectra. Special care is taken to tune the experimental settings (laser power and MCP detector voltage) to minimize observations of any residual material. Consequently, at the standard sensitivity settings (Sect. 2), neither the residue, nor its derivatives, are observed. This leaves the conclusion that the new signals represent newly formed photoproducts arising from $\mathrm{CH}_{3} \mathrm{CN}$ photolysis.

After 2 min of UV photolysis, the mass peak at $\mathrm{m} / \mathrm{z}=67 \mathrm{dom}$ inates the higher region of the mass spectrum. The elemental composition of this ion corresponds to a combination of $\mathrm{CH}_{3} \mathrm{CN}$ and a $\mathrm{CN}$ radical, however, to our knowledge, there are no stable molecules of that composition. This implies that it likely is a fragment of a larger molecule. The simplest scenario is that the fragment at $m / z=67$ is the main fragmentation channel (molecular ion minus $\mathrm{H}$ ) of a molecule with an elemental composition of $\mathrm{C}_{3} \mathrm{~N}_{2} \mathrm{H}_{4}$. An intense $\mathrm{H}$-loss channel upon electron ionization, is typical for nitriles. The only stable candidate found in the NIST database that matches this elemental composition is glycinonitrile, n-methylene- $\mathrm{NCCH}_{2} \mathrm{NCH}_{2}$. Unfortunately, due to a lacking fragmentation pattern, it is not possible to confirm this assignment. At longer irradiation times, additional peaks appear near $m / z=67$, suggesting subsequent (de)hydrogenation reactions $(+2 \mathrm{H}$ or $-2 \mathrm{H})$. Similarly to $\mathrm{m} / \mathrm{z}=67$, it is not possible to unambiguously assign molecular formulas to these ions.

Due to a lack of available data on the fragmentation patterns of large nitriles, the identification of ions at $\mathrm{m} / \mathrm{z}=77-83$, in most cases, follows the assignment of the elemental composition. An exception is succinonitrile $\left(\mathrm{NCCH}_{2} \mathrm{CH}_{2} \mathrm{CN}\right)$, suggested to be a photolysis product in previous studies (Hudson et al. 2008). The fragmentation pattern of $\mathrm{NCCH}_{2} \mathrm{CH}_{2} \mathrm{CN}$, with strong peaks at $\mathrm{m} / \mathrm{z}=79$ and 80 fits the experimental spectrum. The assignment is supported via an available formation pathway: a recombination of two $\mathrm{CH}_{2} \mathrm{CN}$ radicals, which at a high UV fluence, are abundant in the ice. Peaks which are near succinonitrile features differ in the number or hydrogen atoms, but that can be accounted for by $+2 \mathrm{H}$ and $-2 \mathrm{H}$ reactions, resulting in formation of unsaturated nitriles and imines, respectively.

The comparison of mass peak intensities at different temperatures offers a complementary tool for photoproduct assignment. Similarly to previously discussed experiments, $\mathrm{CH}_{3} \mathrm{CN}$ ice is $\mathrm{UV}$ irradiated at $20 \mathrm{~K}$, but in this case, it is warmed up before being probed with LDPI TOF-MS. A comparison of mass spectra at 

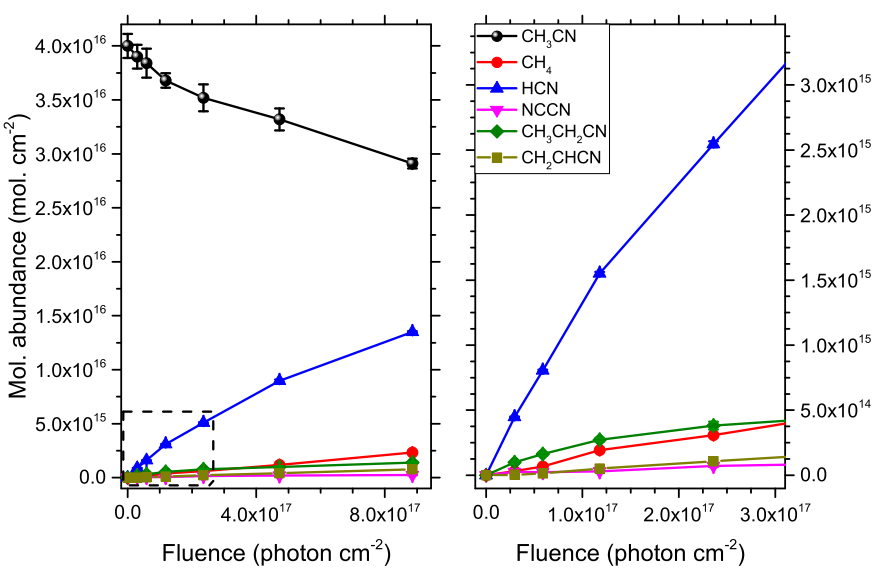

Fig. 4. Left panel: molecular abundances of species during the UV photolysis of $\mathrm{CH}_{3} \mathrm{CN}$ ice as function of photon fluence. Right panel: zoom in of the low fluence region indicated in the left panel.

higher temperatures demonstrates an overall increase in photoproduct abundance, most likely due to the thermally enhanced diffusion in the ice. However, in specific temperature ranges, typically above and below the desorption temperature of an abundantly formed photoproduct, an intensity decrease of characteristic mass peaks is observed. This process can be explained by the thermal desorption of a photoproduct. When comparing mass spectra collected at 30 and $60 \mathrm{~K}$, a decrease in peaks at $\mathrm{m} / \mathrm{z}=15,16$ is observed. This is consistent with thermal desorption of $\mathrm{CH}_{4}$, expected around $40 \mathrm{~K}$. A comparison between mass spectra at 60 and $130 \mathrm{~K}$ shows a decrease in the mass peak at $m / z=27$, which is a characteristic peak of $\mathrm{HCN}$, expected to desorb around $120 \mathrm{~K}$. The integrated (difference) mass spectra demonstrating the thermal desorption of $\mathrm{CH}_{4}$ and $\mathrm{HCN}$ are included in Appendix A. Low abundances of COMs in the ice and the lack of accurate desorption temperatures limited further assignments of photoproducts using this tool.

As mass spectra are recorded for different fluences, it is possible to visualize the formation kinetics for the main $\mathrm{CH}_{3} \mathrm{CN}$ photoproducts $(20 \mathrm{~K})$, listed in Table 2 . The absolute ice abundances are shown in Fig. 4, calibrated using the known initial abundance of the parent molecule. For this purpose, the complete fragmentation patterns of products described above were fitted to our data. This was followed by a consideration of the electron impact ionization cross-sections of the species taken from the NIST database (Kim et al. 2014) or theoretical work (Pandya et al. 2012; Zhou et al. 2019).

The HCN abundance exhibits the fastest increase and appears to be the most abundant product during photolysis. Simultaneously, at a formation rate that is ten times lower, $\mathrm{CH}_{3} \mathrm{CH}_{2} \mathrm{CN}$ and $\mathrm{CH}_{4}$ are formed in the ice. A potential origin of the significant difference in formation yields is discussed in Sect. 3.3. As the photon fluence increases, methane becomes the second most abundant product. The remaining quantified products are: $\mathrm{NCCN} / \mathrm{CNCN}$, and $\mathrm{CH}_{2} \mathrm{CHCN}$, at significantly lower abundances, compared to $\mathrm{HCN}$. The formation of $\mathrm{H}_{2}$ is also observed, however, its yield is largely limited by its thermal desorption. The molecular yields of all quantified photoproducts are summed up to check if the formation of new species balances the loss of the parent molecules. That is indeed the case, hence, despite unidentified peaks appearing in the ice, their contributions to the early chemical network are considered insignificant. The formation kinetics for photoproducts of $\mathrm{CD}_{3} \mathrm{CN}$ at $20 \mathrm{~K}$ (not shown here) demonstrate similar trends.

\section{2. $\mathrm{H}_{2} \mathrm{O}: \mathrm{CH}_{3} \mathrm{CN}$}

Here, two different $\mathrm{H}_{2} \mathrm{O}: \mathrm{CH}_{3} \mathrm{CN}$ ice mixing ratios are used (1:1 and 20:1). Figure 5 shows the calibrated LDPI TOF-MS data of the photolysed water-rich $(20: 1)$ mixture for selected UV fluences. The (black) reference spectrum, before irradiation, shows $\mathrm{m} / \mathrm{z}$ peaks which can be assigned to fragmentation patterns of $\mathrm{H}_{2} \mathrm{O}(\mathrm{m} / \mathrm{z}=16-18), \mathrm{CH}_{3} \mathrm{CN}(\mathrm{m} / \mathrm{z}=12-15,24-28,38-42)$ and protonated clusters of water and water-acetonitrile $(\mathrm{m} / \mathrm{z}=19,37$, $55,60,73)$. The latter are not formed upon UV irradiation but are known to form upon laser desorption. After 2 min of irradiation, an increase in the following mass signals was observed: 27-34, 42-46, 51-60, 75, 76, 93, 94 (see inset of Fig. 5). As the photolysis continues, more peaks are formed. By comparing Figs. 1 and 5, it is immediately clear that the level of molecular complexity is higher in the water containing ice. This is also expected. Upon UV irradiation, the ice contains $\mathrm{OH}$ radicals, as well as $\mathrm{O}$ - and $\mathrm{H}$-atoms that will expand the chemical network. A systematic analysis of the resulting data is given below.

A comparison of the pure and mixed ice (1:1) allows us to identify mass peaks that can be associated with water chemistry. In the water-dominated experiments (20:1), the abundance of these products is expected to further increase. This information, combined with TOF spectra obtained for the $\mathrm{H}_{2}{ }^{18} \mathrm{O}$ experiments, allows us to assign the elemental compositions of the produced species. Finally, considering the reactions expected to take place in the ice mixture, specific mass peaks can be linked to specific (fragments of) photoproducts, similar to the approach used for pure ices. Table 3 shows a summary of all observed mass peaks and their corresponding elemental compositions.

The results of four different photolysis experiments feature: pure $\mathrm{CH}_{3} \mathrm{CN}$ ice, two different $\mathrm{H}_{2} \mathrm{O}: \mathrm{CH}_{3} \mathrm{CN}$ mixtures $(1: 1$ and 20:1) and $\mathrm{a}_{2}{ }^{18} \mathrm{O}: \mathrm{CH}_{3} \mathrm{CN}$ mixture (20:1), as shown in Figs. 6-8. Each figure shows a different mass range and we note that Fig. 6 shows the intermediate range (37-50 amu) and in Figs. 7 and 8, a lower (24-37 amu) and higher (50-70 amu) mass regime, respectively. In order to compare relative yields of products between the four experiments, all mass spectra are normalized to the amount of $\mathrm{CH}_{3} \mathrm{CN}$ in the ice via the mass peak signal at $m / z=39$. This particular peak is chosen as a signature of acetonitrile, as it does not with overlap with any other fragments of species present in the ice.

Figure 6 shows a mass spectral range between $m / z=37-50$. Peaks at 38-42 amu are a part of the fragmentation pattern of $\mathrm{CH}_{3} \mathrm{CN}$ ice. The UV irradiation of the (1:1) ice mixture yields new mass peaks at $\mathrm{m} / \mathrm{z}=45-48$ and signals at $\mathrm{m} / \mathrm{z}=42-44$ are significantly higher than in the pure ice experiment. The new peaks hint at the presence of O-bearing species, which is consistent with the TOF spectra found for the water dominated experiment (20:1). A comparison of the (20:1) spectra for the ${ }^{16} \mathrm{O}$ and ${ }^{18} \mathrm{O}$ water shows that not all product peaks (42-48 amu) can be assigned to O-bearing species, as only part of the peaks shifts upon ${ }^{18} \mathrm{O}$ substitution.

The observed peak shifts, corresponding to 2 or 4 amu, indicate that $\mathrm{O}$-bearing species or fragments are involved with one or two oxygen atoms. The corresponding elemental compositions are: $\mathrm{CHNO}, \mathrm{CH}_{3} \mathrm{NO}, \mathrm{CO}_{2} \mathrm{H}_{2 x}$, and $\mathrm{C}_{2} \mathrm{H}_{y} \mathrm{O}$ (where $x=0,2$ and $y=4,6)$. Based on the characteristic mass peaks of all considered species, these compositions can be assigned to isocyanic acid ( $\mathrm{HNCO})$, carbon dioxide $\left(\mathrm{CO}_{2}\right)$, acetaldehyde $\left(\mathrm{CH}_{3} \mathrm{CHO}\right)$, dimethyl ether $\left(\mathrm{CH}_{3} \mathrm{OCH}_{3}\right)$, ethanol $\left(\mathrm{CH}_{3} \mathrm{CH}_{2} \mathrm{OH}\right)$, and formic acid $(\mathrm{HCOOH})$. Formamide $\left(\mathrm{NH}_{2} \mathrm{CHO}\right)$ is one of the candidates fitting the $\mathrm{CH}_{3} \mathrm{NO}$ composition, and several possible solid state formation routes have been discussed before (Raunier et al. 2004; 


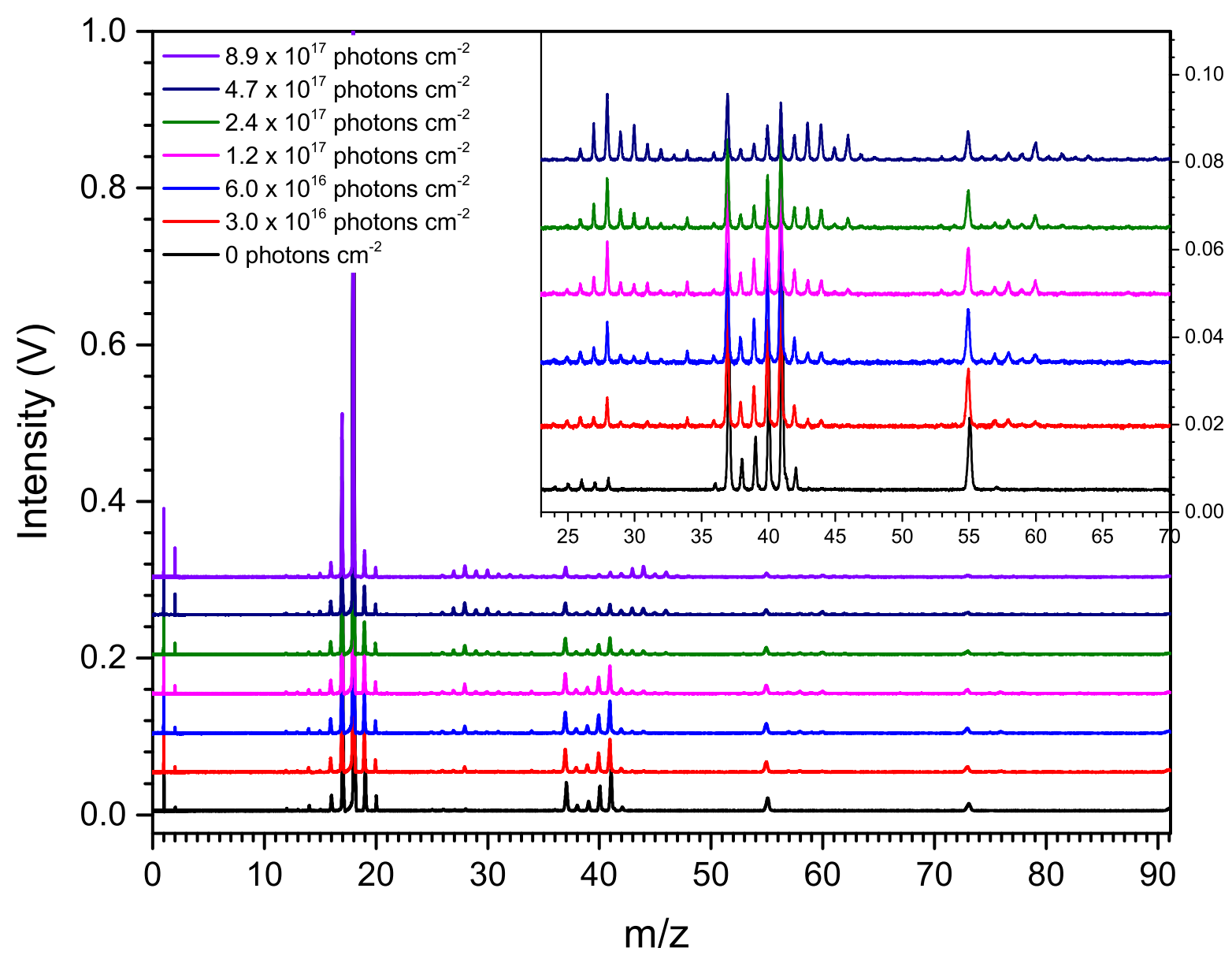

Fig. 5. LDPI TOF-MS signals for an UV irradiated $\mathrm{H}_{2} \mathrm{O}: \mathrm{CH}_{3} \mathrm{CN}$ (20:1) ice at $20 \mathrm{~K}$ for increasing photon fluence. The lowest graph shows the signal without UV irradiation. The inset is a zoom on the intensity scale for the higher masses.

Jones et al. 2011; Ligterink et al. 2018), but other isomers cannot be excluded at this stage. The assignment of the elemental formula HCNO to isocyanic acid is guided by a study by Gerakines et al. (2004) and the greater stability of HNCO versus its isomers shown by Crowley \& Sodeau (1989).

The contribution from other species in the $m / z=42-48$ range is only clearly visible in the ${ }^{18} \mathrm{O}$ experiments. All oxygen containing species shift to $\mathrm{m} / \mathrm{z}=45$ or higher, while peaks at 42 , 43 , and 44 remain present in the spectra. The molecules that contribute to these peaks lack oxygen. Considering the parent species, it was concluded that these mass signals originate from imines (containing the $=\mathrm{NH}$ functional group) and amines (containing the $-\mathrm{NH}_{2}$ group). It is important to note that as the signals in the ${ }^{18} \mathrm{O}$ experiments are generally less intense, partially due to the presence of $3 \%$ of ${ }^{16} \mathrm{O}$, this does not account for the observed signals at $m / z=42-44$.

Formation of imines and amines in the ice might proceed via excited radicals reacting with the $\mathrm{C} \equiv \mathrm{N}$ bond of $\mathrm{CH}_{3} \mathrm{CN}$, for instance:

$$
\begin{aligned}
& \mathrm{CH}_{3} \mathrm{CN}+2 \mathrm{H} \rightarrow \mathrm{CH}_{3} \mathrm{CHNH}, \\
& \mathrm{CH}_{3} \mathrm{CHNH}+2 \mathrm{H} \rightarrow \mathrm{CH}_{3} \mathrm{CH}_{2} \mathrm{NH}_{2} .
\end{aligned}
$$

A similar process was demonstrated for $\mathrm{HCN}$, which undergoes hydrogenation reactions, even with cold atoms, to form $\mathrm{CH}_{2} \mathrm{NH}_{2}$ (Theule et al. 2011).

The present work demonstrates, for the first time, the hydrogenation of a $\mathrm{C} \equiv \mathrm{N}$ bond for larger nitriles. The formation of imines and amines seems to be significantly enhanced in the presence of water ice. This has two major consequences. Firstly, it underlines the "catalytic" potential of water ice. Secondly, it implies that $=\mathrm{NH}$ and $-\mathrm{NH}_{2}$ functional groups are present in the ice, which helps with interpreting the mass signals in the other mass ranges. The addition of water into the ice mixture clearly increases the number of possible chemical pathways and is further discussed in Sect. 3.4.

Figure 7 shows a lower mass range $(\mathrm{m} / \mathrm{z}=24-37)$, which is the signature region of smaller COMs. A comparison of the UV irradiated pure and mixed ices (1:1), shows that new mass signals appear at $\mathrm{m} / \mathrm{z}=31,32,33$, while at $\mathrm{m} / \mathrm{z}=29$ and 30 significantly higher signals are found. The peak at $\mathrm{m} / z=32$, which further increases with water content (20:1) is determined to have an elemental composition of $\mathrm{CH}_{4} \mathrm{O}$. With $\mathrm{CH}_{3}$ and $\mathrm{OH}$ radicals available in the ice, the most logical explanation is that this peak corresponds to the ionized methanol $\left(\mathrm{CH}_{3} \mathrm{OH}^{+}\right)$. This assignment is consistent with the shift of the peak $(\mathrm{m} / \mathrm{z}=32$ to $m / z=34)$ in the ${ }^{18} \mathrm{O}$ experiments and with the increasing intensity of the methanol base peak $(\mathrm{m} / \mathrm{z}=31$, shifted to $m / z=33$ ), although it should be noted that this peak is also characteristic for fragment masses of larger COMs. The formation of methanol also indicates that $\mathrm{CH}_{3} \mathrm{OH}$ photoproducts as studied by Öberg et al. (2009) and Paardekooper et al. (2016a) can be expected as well.

The mass peak at $m / z=33$ is due to species with an elemental composition of $\mathrm{NH}_{3} \mathrm{O}$. The molecular ion of hydroxylamine $\left(\mathrm{NH}_{2} \mathrm{OH}\right)$ could be a carrier of this signal, as is the case for 
Table 3. Characteristic $\mathrm{m} / \mathrm{z}$ peaks used for identification of photoproducts of the UV photolysis of the $\mathrm{H}_{2} \mathrm{O}: \mathrm{CH}_{3} \mathrm{CN}(1: 1$ and $20: 1)$ and $\mathrm{H}_{2}{ }^{18} \mathrm{O}: \mathrm{CH}_{3} \mathrm{CN}(20: 1)$ ices.

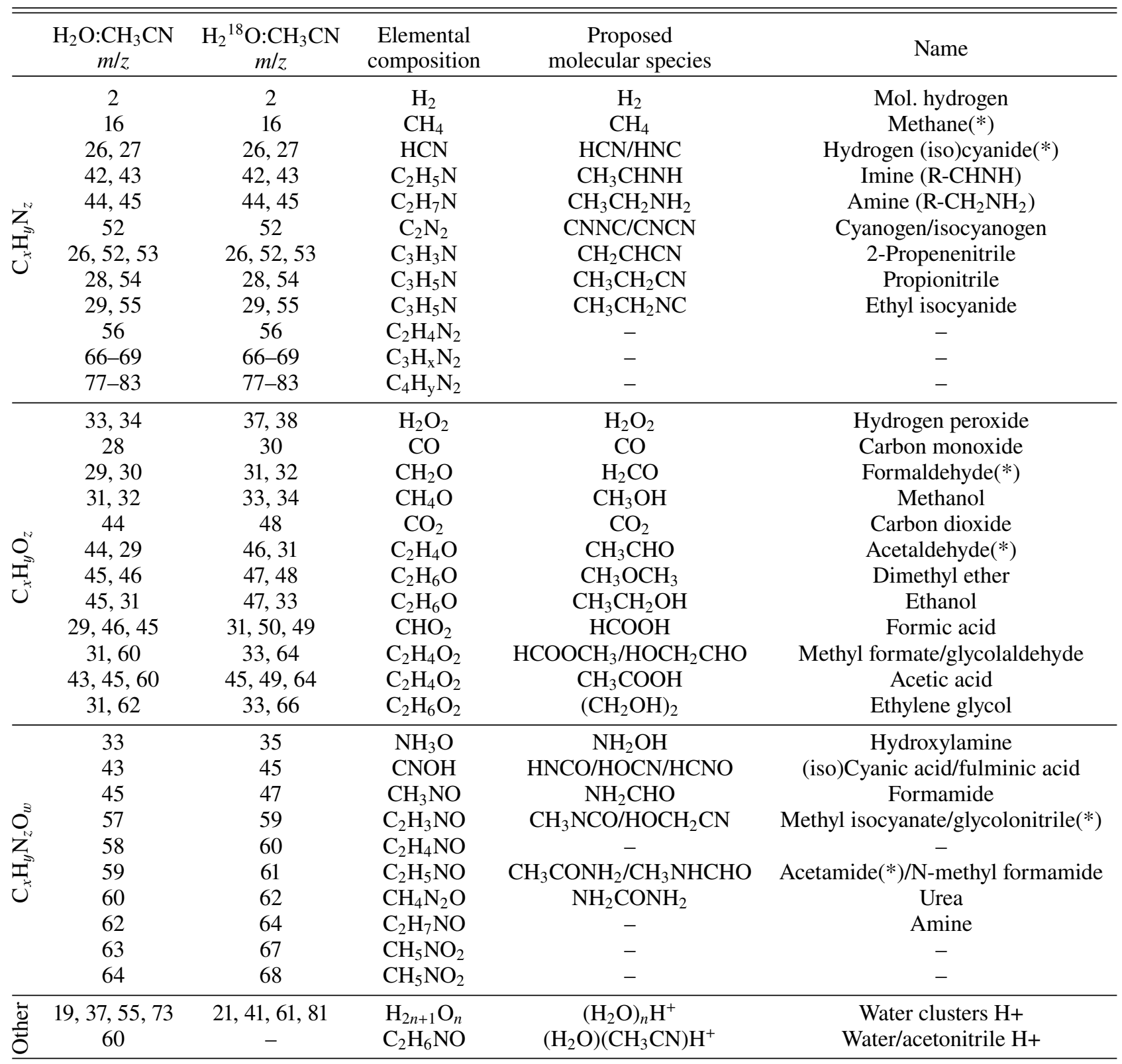

Notes. Species previously detected using gas chromatography-mass spectrometry (GC-MS) after energetic processing of $\mathrm{H}_{2} \mathrm{O}: \mathrm{CH}_{3} \mathrm{CN}$ ice are marked with an asterisk (*) based on Hudson et al. (2008).

protonated methanol or a fragment of hydrogen peroxide $\left(\mathrm{H}_{2} \mathrm{O}_{2}\right)$. Contributions of the latter two are less likely, as mass signals at $\mathrm{m} / \mathrm{z}=32$ (unfragmented methanol) and 34 (unfragmented hydrogen peroxide) are relatively low. In a previous work, $\mathrm{NH}_{2} \mathrm{OH}$ was shown to form through hydrogenation of NO (Fedoseev et al. 2012) and was recently detected in space (Rivilla et al. 2020).

In the case of peaks $m / z=28-30$, an increase is due to multiple species. The most likely contributors include carbon monoxide $(\mathrm{CO}) / \mathrm{N}_{2}$, formaldehyde $\left(\mathrm{H}_{2} \mathrm{CO}\right)$, methanimine $\left(\mathrm{CH}_{2} \mathrm{NH}\right)$, and fragments of bigger COMs. Specifically, primary amines have their characteristic, strong fragment at $\mathrm{m} / \mathrm{z}=30$ $\left(\mathrm{CH}_{2} \mathrm{NH}_{2}\right)$. For the water-dominated experiments, the ratio of 29 to 30 is reversed upon longer photolysis, which may reflect a growing presence of a family of primary amines. All these assignments are also consistent for experiments with increased water content and (non)shifts observed for ${ }^{18} \mathrm{O}$.

From Fig. 8, it becomes clear that the higher mass range, $m / z=51-65$, exhibits a picture of chemical complexity that is largely consistent with the lower mass range. Peaks at $m / z=51-$ 57 , associated with nitriles containing three $\mathrm{C}$-atoms, are present in both the pure ice photolysis and in the 1:1 ice mixture. In the water-dominated experiment (20:1), these are almost non detectable, most likely due to an overabundance of water, which lowers the probability for $\mathrm{CH}_{3} \mathrm{CN}$ molecules to stay next to each other in the ice.

New peaks, compared to the pure acetonitrile photolysis, appear at $m / z=58-60$ and the peak at $\mathrm{m} / z=57$ is significantly more pronounced. Additionally, water-dominated experiments 

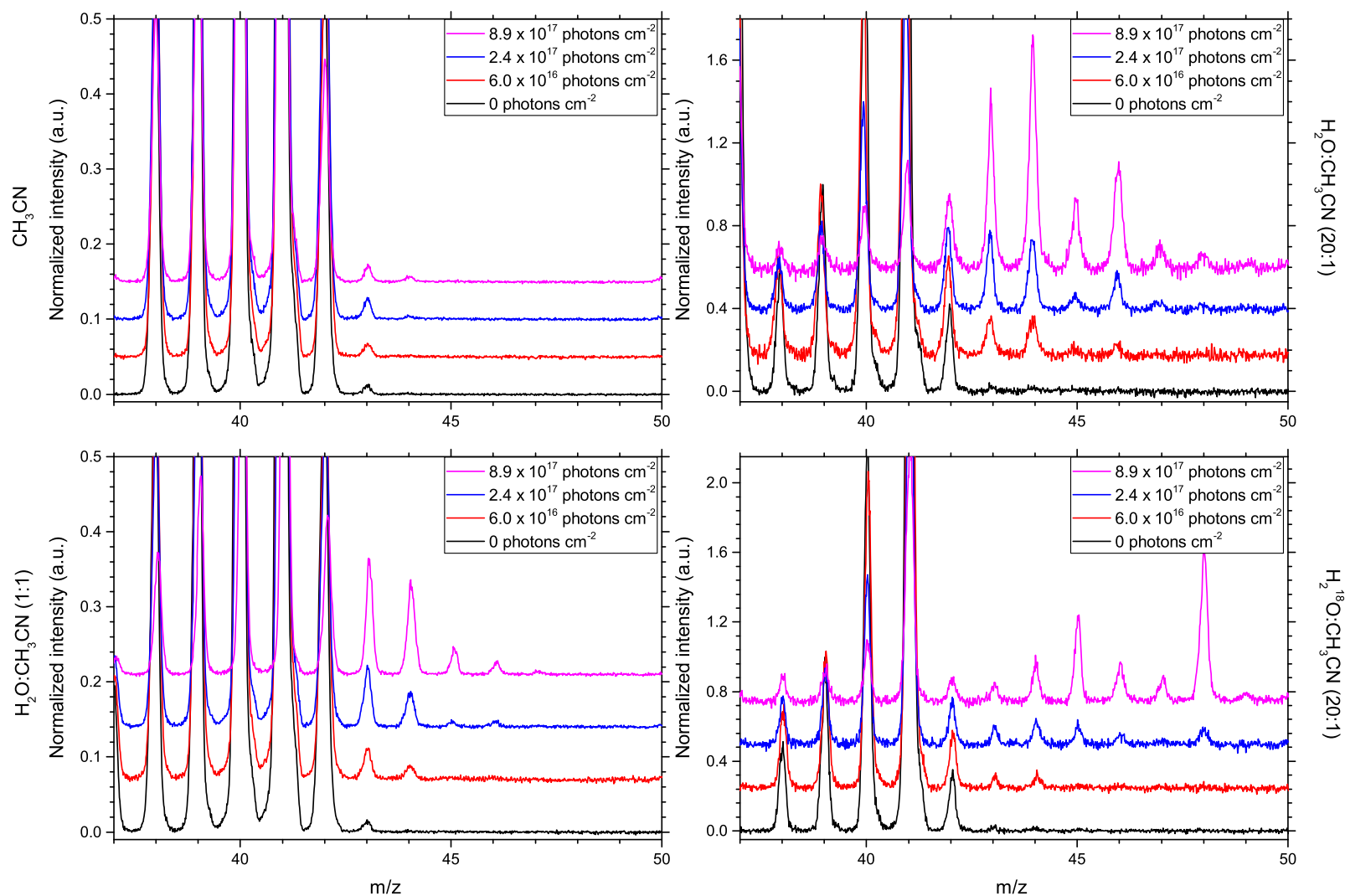

Fig. 6. Normalized LDPI TOF-MS signals ( $\mathrm{m} / \mathrm{z}$ range: $37-50)$ for four different photolysis experiments. Top panel from left to right: $\mathrm{CH}_{3} \mathrm{CN}$, $\mathrm{H}_{2} \mathrm{O}: \mathrm{CH}_{3} \mathrm{CN}$ (20:1). Bottom panel from left to right: $\mathrm{H}_{2} \mathrm{O}: \mathrm{CH}_{3} \mathrm{CN}(1: 1)$ and $\mathrm{CH}_{3} \mathrm{CN}: \mathrm{H}_{2}{ }^{18} \mathrm{O}(20: 1)$.
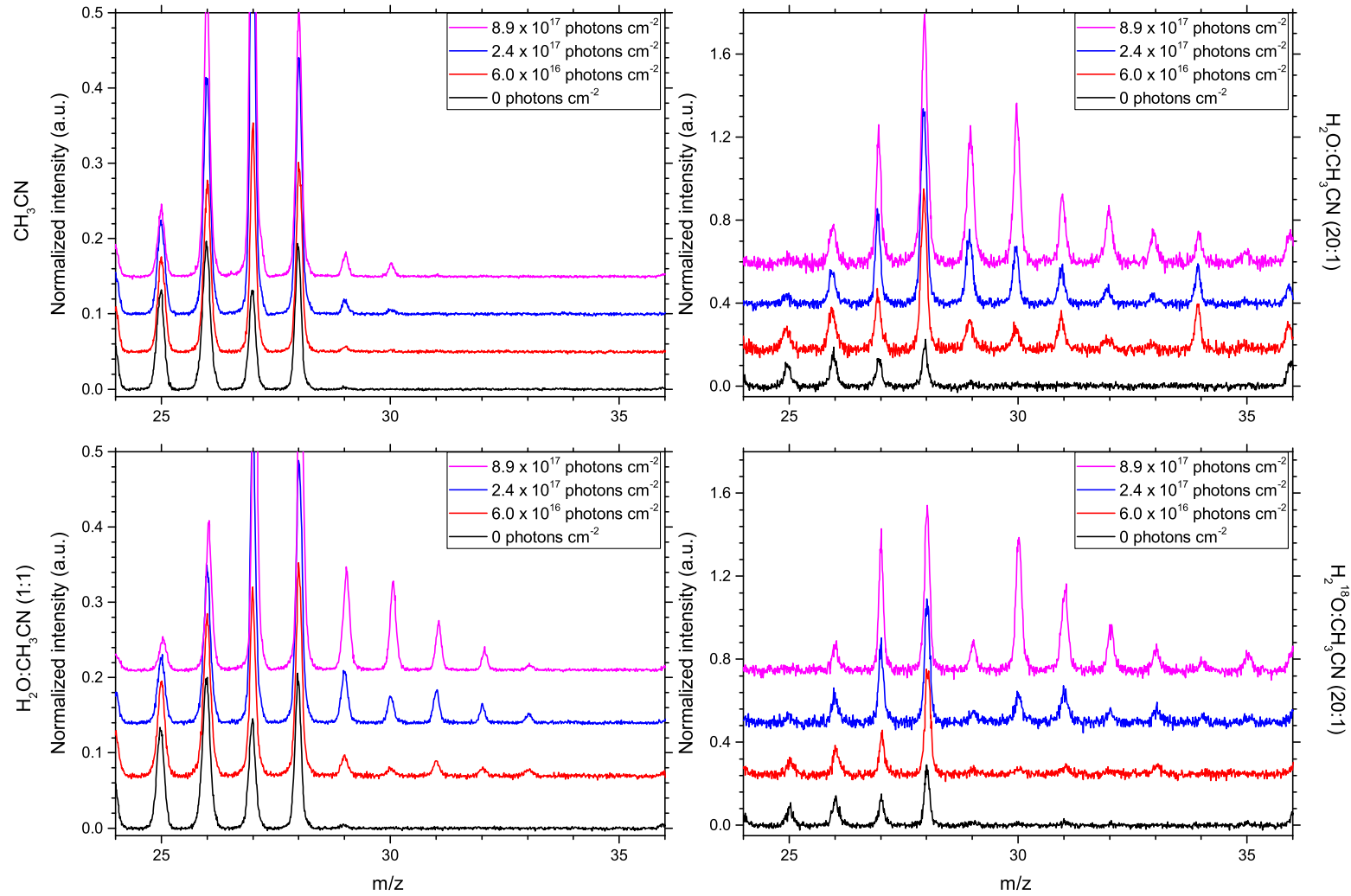

Fig. 7. Normalized LDPI TOF-MS signals(m/z range: 24-37) for four different photolysis experiments. Top panel from left to right: $\mathrm{CH}_{3} \mathrm{CN}_{\text {, }}$ $\mathrm{H}_{2} \mathrm{O}: \mathrm{CH}_{3} \mathrm{CN}$ (20:1). Bottom panel from left to right: $\mathrm{H}_{2} \mathrm{O}: \mathrm{CH}_{3} \mathrm{CN}(1: 1)$ and $\mathrm{CH}_{3} \mathrm{CN}_{2}: \mathrm{H}_{2}{ }^{18} \mathrm{O}(20: 1)$. 

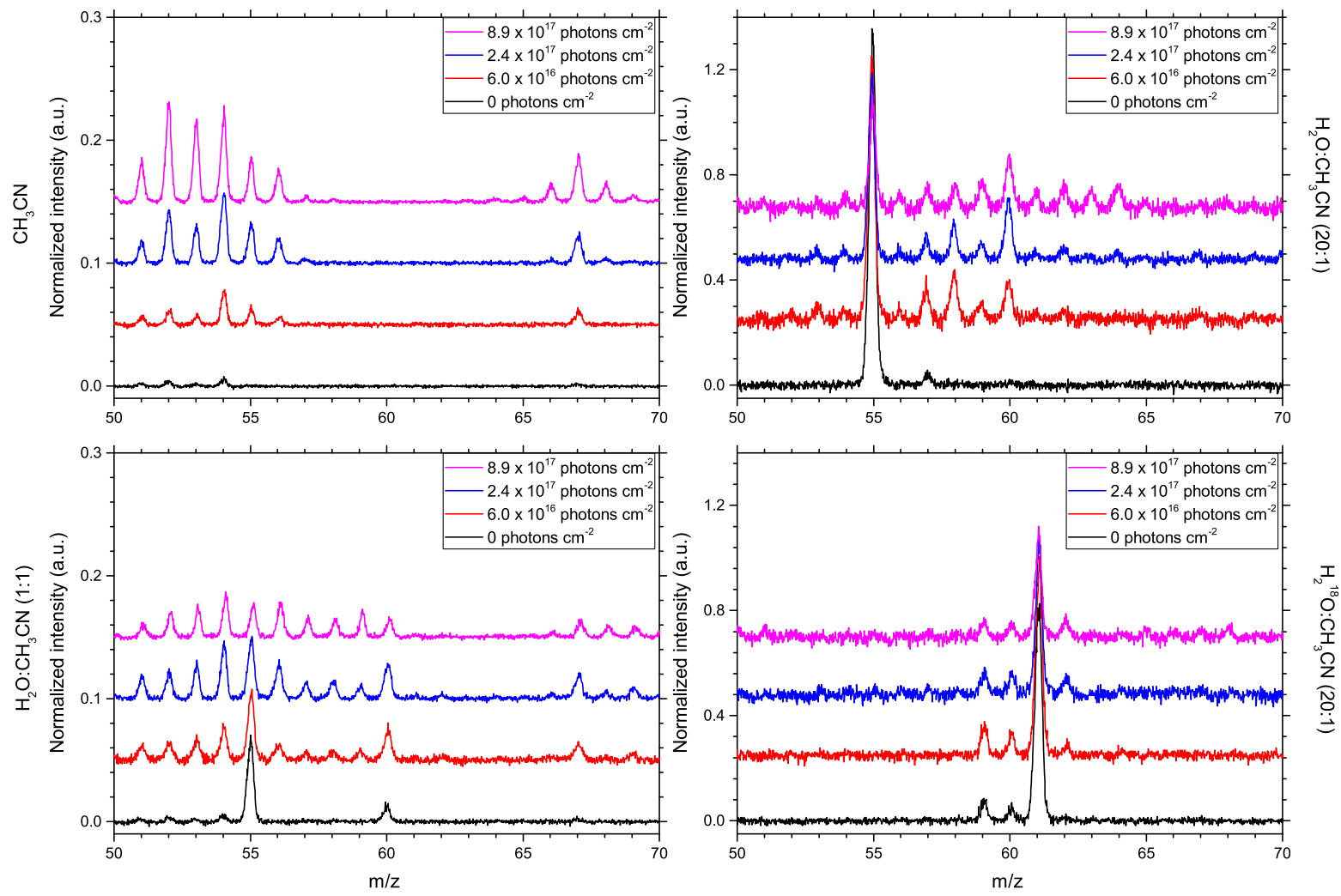

Fig. 8. Normalized LDPI TOF-MS signals $(\mathrm{m} / \mathrm{z}$ range: $50-70)$ for four different photolysis experiments. Top panel from left to right: $\mathrm{CH}_{3} \mathrm{CN}$, $\mathrm{H}_{2} \mathrm{O}: \mathrm{CH}_{3} \mathrm{CN}$ (20:1). Bottom panel from left to right: $\mathrm{H}_{2} \mathrm{O}: \mathrm{CH}_{3} \mathrm{CN}(1: 1)$ and $\mathrm{CH}_{3} \mathrm{CN}: \mathrm{H}_{2}{ }^{18} \mathrm{O}(20: 1)$.

give way to new peaks at $m / z=61-64$. Assigning elemental compositions to all peaks in this mass range $(\mathrm{m} / \mathrm{z}=51-65)$ is challenging due to low signals of the ${ }^{18} \mathrm{O}$ experiments, however, a few conclusions can be drawn. The peak at $\mathrm{m} / \mathrm{z}=57$, for which a strong contribution from O-bearing species is visible, has an elemental composition of $\mathrm{C}_{2} \mathrm{H}_{3} \mathrm{NO}$. There are several species consistent with this composition but the most likely candidates are glycolonitrile $\left(\mathrm{HOCH}_{2} \mathrm{CN}\right)$ and methyl isocyanate $\left(\mathrm{CH}_{3} \mathrm{NCO}\right)$. The first structure can be a direct result of a radical recombination $\left(\mathrm{OH}+\mathrm{CH}_{2} \mathrm{CN}\right)$ and the latter can be formed through an $\mathrm{O}$-atom interacting with the triple bond of $\mathrm{CH}_{3} \mathrm{CN}$ or its structural isotope, $\mathrm{CH}_{3} \mathrm{NC}$. The assignment of $\mathrm{CH}_{3} \mathrm{NCO}$ is also supported by a recent study by Fourré et al. (2020), in which the relative thermodynamical stability of 40 isotopes of $\mathrm{C}_{2} \mathrm{H}_{3} \mathrm{NO}$ is compared. The clearly visible peak at $\mathrm{m} / \mathrm{z}=58$ is associated with an elemental composition of $\mathrm{C}_{2} \mathrm{H}_{4} \mathrm{NO}$, which is confirmed with a shift to $m / z=60$. Considering the available molecular reservoir, the peak at $\mathrm{m} / \mathrm{z}=59$ can be assigned to an elemental composition of $\mathrm{C}_{2} \mathrm{H}_{5} \mathrm{NO}$. Newly formed species that are consistent with this observation include acetamide $\left(\mathrm{CH}_{3} \mathrm{CONH}_{2}\right)$ and $\mathrm{N}$-methyl formamide $\left(\mathrm{CH}_{3} \mathrm{NHCHO}\right)$, with the first molecule being the most stable isomer (Lattelais et al. 2010). These may form in $\mathrm{O} / \mathrm{OH}$ radical reactions involving $\mathrm{CH}_{3} \mathrm{CN}$ and its structural isomer $\mathrm{CH}_{3} \mathrm{NC}$, followed by $\mathrm{H}$-atom additions, but as the involved energetics are unknown, such a conclusion only can be treated with care.

Peak 60, which significantly increases for water dominated ices, can be explained by contributions from two stable combinations of elements: $\mathrm{C}_{2} \mathrm{H}_{4} \mathrm{O}_{2}$ or $\mathrm{CH}_{4} \mathrm{~N}_{2} \mathrm{O}$. The peak shifts observed in the ${ }^{18} \mathrm{O}$ experiments, point to a major contribution from the species with one oxygen atom. One of the structures that is potentially present is a molecule of astrobiological context, urea $\left(\mathrm{NH}_{2} \mathrm{CONH}_{2}\right)$. This would be consistent with the Wohler synthesis. The previously demonstrated formation pathways of urea on interstellar grains analogues includes radical recombination of $\mathrm{NH}_{2}$ and $\mathrm{CONH}_{2}$ (Raunier et al. 2004; Ligterink et al. 2018).

In water-dominated experiments, additional peaks appear at $m / z=61-64$. These peaks are shifted to 64-68 range in the ${ }^{18} \mathrm{O}$ experiments, indicating a presence of two oxygen atoms in the fragments. A possible corresponding elemental composition is $\mathrm{CH}_{x} \mathrm{NO}_{2}$, where $x=3-5$.

The chemical complexity continues to increase as many peaks are seen in the higher $\mathrm{m} / \mathrm{z}$ range. This indicates that upon UV irradiation of $\mathrm{CH}_{3} \mathrm{CN}$ (embedded in water) ices, even larger COMs with at least six or more $\mathrm{C}$-, $\mathrm{N}$-, and $\mathrm{O}$-atoms are formed. A specific assignment is not possible at this stage, but this observation on its own is interesting, as it shows that $\mathrm{CH}_{3} \mathrm{CN}$ can act as an efficient precursor species in the formation of large $\mathrm{N}$-containing COMs.

\subsection{Abstraction reactions in the ice at $20 \mathrm{~K}$}

The most abundant product of the photolysis of pure $\mathrm{CH}_{3} \mathrm{CN}$ ice is HCN. In order to compare the HCN yield between different experiments, it is helpful to convert the molecular yields to formation rates in molecules per absorbed photon. For this, average photon absorption cross sections in the range $120-165 \mathrm{~nm}$ are used, which, for $\mathrm{CH}_{3} \mathrm{CN}$ and $\mathrm{H}_{2} \mathrm{O}$ are $7.5 \times 10^{-18}$ photons $\mathrm{cm}^{-2}$ and $2.3 \times 10^{-18}$ photons $\mathrm{cm}^{-2}$. For mixed ices, the absorption cross section is derived as an average between the constituents, considering the ratio between them. The efficiency of $\mathrm{HCN}$ 
formation, per destroyed $\mathrm{CH}_{3} \mathrm{CN}$, per absorbed photon, is similar for all studied ices. On average, 1000 absorbed photons lead to the destruction of $230 \mathrm{CH}_{3} \mathrm{CN}$ molecules and the formation of $200 \mathrm{HCN}$ molecules, almost ten times the amount of $\mathrm{CH}_{4}$.

The dominating yield of HCN motivates further investigation of its formation route. The radical recombination formation pathway of $\mathrm{HCN}$ requires photodissociation of two $\mathrm{CH}_{3} \mathrm{CN}$ molecules ( $\mathrm{CN}+\mathrm{H}$ recombination). Additionally, if radical recombination is the dominant reaction mechanism, the $\mathrm{CH}_{4}$ formation yield should be comparable $\left(\mathrm{CH}_{3}+\mathrm{H}\right.$ route). The calculated yields are not in line with a radical-radical recombination scenario, thus, other reaction types need to be considered.

One of the alternative formation routes is an abstraction reaction with the general formula: $\mathrm{H}-\mathrm{X}+\mathrm{CN} \rightarrow \mathrm{X}+\mathrm{HCN}$, where $\mathrm{X}$ can be $\mathrm{CH}_{2} \mathrm{CN}, \mathrm{CH}_{3}$, etc. This reaction of $\mathrm{CH}_{2} \mathrm{CN}$ and a $\mathrm{CN}$ radical resulting in formation of $\mathrm{HCN}$ is strongly exothermic $\left(99 \mathrm{~kJ}\right.$ mole $\left.{ }^{-1}\right)$, while a similar reaction including a $\mathrm{CH}_{3}$ radical, and resulting in $\mathrm{CH}_{4}$ formation, is barely exothermic $\left(8 \mathrm{~kJ} \mathrm{~mole}^{-1}\right)$. The calculations of enthalpies are based on values from Active Thermochemical Tables available via the Argonne National Laboratory (Ruscic et al. 2004). This helps to account for a major difference in production rates of $\mathrm{HCN}$ and $\mathrm{CH}_{4}$. A theoretical study will be necessary to test which is the most efficient formation mechanism of $\mathrm{HCN}$ in the $\mathrm{H}_{2} \mathrm{O}: \mathrm{CH}_{3} \mathrm{CN}$ ice. The reaction type discussed above, of an excited radical with a neutral species, has been recently demonstrated to be efficient also at low temperatures for gas phase $\mathrm{CH}_{3} \mathrm{OH}+\mathrm{OH}$ and $\mathrm{CH}_{3} \mathrm{CN}+\mathrm{CN}$ (Shannon et al. 2013; Sleiman et al. 2016). Hence, this type of reactions should be considered in gas-grain astrochemical models, which is already the case in recent work by Jin \& Garrod (2020).

\subsection{Role of water in ice chemistry}

Water, as the most abundant constituent of interstellar ice, plays an important role in the solid state chemical networks. The effects of water molecules on the ice chemistry observed in this work are in agreement with previous studies (e.g., Öberg et al. 2010). In particular, it is found that the formation of O-rich species is increased with the water content. In the waterdominated experiment, $\mathrm{m} / \mathrm{z}=44$ is assigned to species containing two $\mathrm{O}$ atoms, consistent with the observed shift to $\mathrm{m} / \mathrm{z}=48$, for ${ }^{18} \mathrm{O}$ experiments. This peak, assigned to $\mathrm{CO}_{2}$, is less intense in the mixture with $1: 1$ ratio, in comparison to the mixture with 20:1 ratio, and is not present in the pure $\mathrm{CH}_{3} \mathrm{CN}$ ice photolysis. Other O-bearing species exhibit a similar behaviour, which follows the water abundance in the ice. Consequently, as $\mathrm{CH}_{3} \mathrm{CN}$ molecules are more diluted in a water-rich ice, the abundance of nitrile based photoproducts (e.g., $\mathrm{CH}_{3} \mathrm{CH}_{2} \mathrm{CN}$ ) decreases proportionally.

The quantitative analysis of influence of water on the ice kinetics is limited to molecules with known mass spectra (formed upon dissociative ionization) and minimum overlap of characteristic $\mathrm{m} / \mathrm{z}$ peaks with any other products. Hence, it was possible to determine the kinetics for the parent molecule $\left(\mathrm{CH}_{3} \mathrm{CN}\right)$ in each experiment and a limited number of photoproducts $\left(\mathrm{CH}_{3} \mathrm{OH}, \mathrm{HCN}\right)$ in the experiments with mixed ices. This data is presented in Appendix B.

$\mathrm{H}_{2} \mathrm{O}$ ice provides an environment in which nitriles can efficiently transform into imines and amines, upon UV-photolysis. Previous studies already reported on these findings. An isomerization of $\mathrm{CH}_{3} \mathrm{CN}$ to an imine was demonstrated during $\mathrm{UV}$ photolysis by Hudson \& Moore (2004), however, this was not studied in the water environment. In another study, Nguyen et al.
(2019) performed an experimental and theoretical investigation of hydrogenation of $\mathrm{CH}_{3} \mathrm{CN}$. The study demonstrated a high energy barrier for hydrogenating the $\mathrm{C} \equiv \mathrm{N}$ bond: between 0.06 $0.22 \mathrm{eV}$, depending on the used level of theory. The analysis of the mass spectra in Fig. 6 shows evidence for effective hydrogenation of the $\mathrm{C} \equiv \mathrm{N}$ bond, which leads to formation of imines and amines, in a water-rich ice. This must be due to the energetic radicals produced in photodissociation of the water molecules. Indeed, the average translation energy carried by an $\mathrm{H}$ radical following water dissociation is between 1.5 and $2.5 \mathrm{eV}$ (Andersson \& van Dishoeck 2008), larger than the calculated barrier of $0.22 \mathrm{eV}$. Following the first hydrogenation of the $\mathrm{C} \equiv \mathrm{N}$ bond, subsequent $\mathrm{H}$ atom additions have a lower energetic barrier, which eventually leads to a formation of imines and amines.

The chemical complexity observed in the photolyzed mixed ices goes beyond amines, specifically the formation of amides (molecules containing the $-\mathrm{C}(=\mathrm{O}) \mathrm{NH}_{2}$ functional group) is observed. During the photolysis of the mixed ices, the mass peaks associated with amides $(\mathrm{m} / \mathrm{z}=57-59)$ appear after 2 min of irradiation (see Fig. 8), hence, a formation pathway involving many steps is unlikely. Here, we suggest that the formation of amides takes place via O-/OH-radical interacting with the triple bond of $\mathrm{CH}_{3} \mathrm{CN}$. Photodissociation of $\mathrm{H}_{2} \mathrm{O}$ using photons in an energy range $8.5-10.5 \mathrm{eV}$ leads to an electronically excited $\mathrm{OH}\left(\mathrm{A}^{2}\right)$ and $\mathrm{O}\left({ }^{1} \mathrm{D}\right)$ (van Harrevelt \& van Hemert 2008), which can interact with the $\mathrm{C} \equiv \mathrm{N}$ bond to form amides. This chemical route, however, requires further verification. At least two other pathways to form amides are known. Both might be more relevant towards the end of our experiments, as multiple chemical steps are involved. One pathway is demonstrated by Ligterink et al. (2018), where the formation of $\mathrm{CH}_{3} \mathrm{CONH}_{2}$ proceeds via the recombination of the $\mathrm{NH}_{2} \mathrm{CO}$ radical (formed from $\mathrm{NH}_{2}+\mathrm{CO}$ ) with a $\mathrm{CH}_{3}$ radical. An alternative route is through breaking of the $\mathrm{C}-\mathrm{OH}$ bond in any carboxylic acid (e.g., acetic acid, $\mathrm{CH}_{3} \mathrm{COOH}$ ) and attaching a $-\mathrm{NH}, \mathrm{NH}_{2}$ or $-\mathrm{NRH}$ (from ammonia or any amine) to the leftover $\mathrm{C}=\mathrm{O}$ structure will yield formamide $\left(\mathrm{NH}_{2} \mathrm{CHO}\right)$.

\section{Astrophysical implications}

$\mathrm{N}$-bearing COMs are commonly observed towards diverse environments, yet the chemical network leading to their formation is still unclear. An observational study focused on the origin of $\mathrm{N}$-bearing COMs in the Galactic Center quiescent giant molecular cloud, $\mathrm{G}+0.693$ by Zeng et al. (2018) concluded that species such as $\mathrm{CH}_{3} \mathrm{CN}, \mathrm{HC}_{5} \mathrm{~N}, \mathrm{HNCO}$, and $\mathrm{NH}_{2} \mathrm{CHO}$ are transferred to the gas phase from dust grains. The gas phase abundances of $\mathrm{CH}_{3} \mathrm{CN}$ observed in protoplanetary disks, photodissociation regions (PDR), and dark, dense molecular cores, also imply that $\mathrm{CH}_{3} \mathrm{CN}$ is released from icy mantles (Loomis et al. 2018; Gratier et al. 2013). These findings are in agreement with the laboratory work presented here that shows that upon vacuum UV irradiation of $\mathrm{H}_{2} \mathrm{O}: \mathrm{CH}_{3} \mathrm{CN}$ ice a large amount of $\mathrm{N}$-bearing COMs can be formed. This is not fully unexpected, as the molecular structure of acetonitrile $\left(\mathrm{CH}_{3}-\mathrm{CN}\right)$ resembles that of methanol $\left(\mathrm{CH}_{3}-\mathrm{OH}\right)$ that has been shown to be an important parent molecule to O-bearing COMs. Actually, as methanol is found to be formed upon UV photolysis of $\mathrm{H}_{2} \mathrm{O}: \mathrm{CH}_{3} \mathrm{CN}$ ice, the experiments analyzed here also offer pathways towards O-(and N/O-)bearing COMs. It should be noted, however, that methanol is more abundant than $\mathrm{CH}_{3} \mathrm{CN}$; also, other nitrogen precursors, such as NO and $\mathrm{NH}_{x}$ radicals, may play a role in the formation of $\mathrm{N}$-bearing COMs (see e.g., Congiu et al. 2012; Mu noz Caro et al. 2014; 


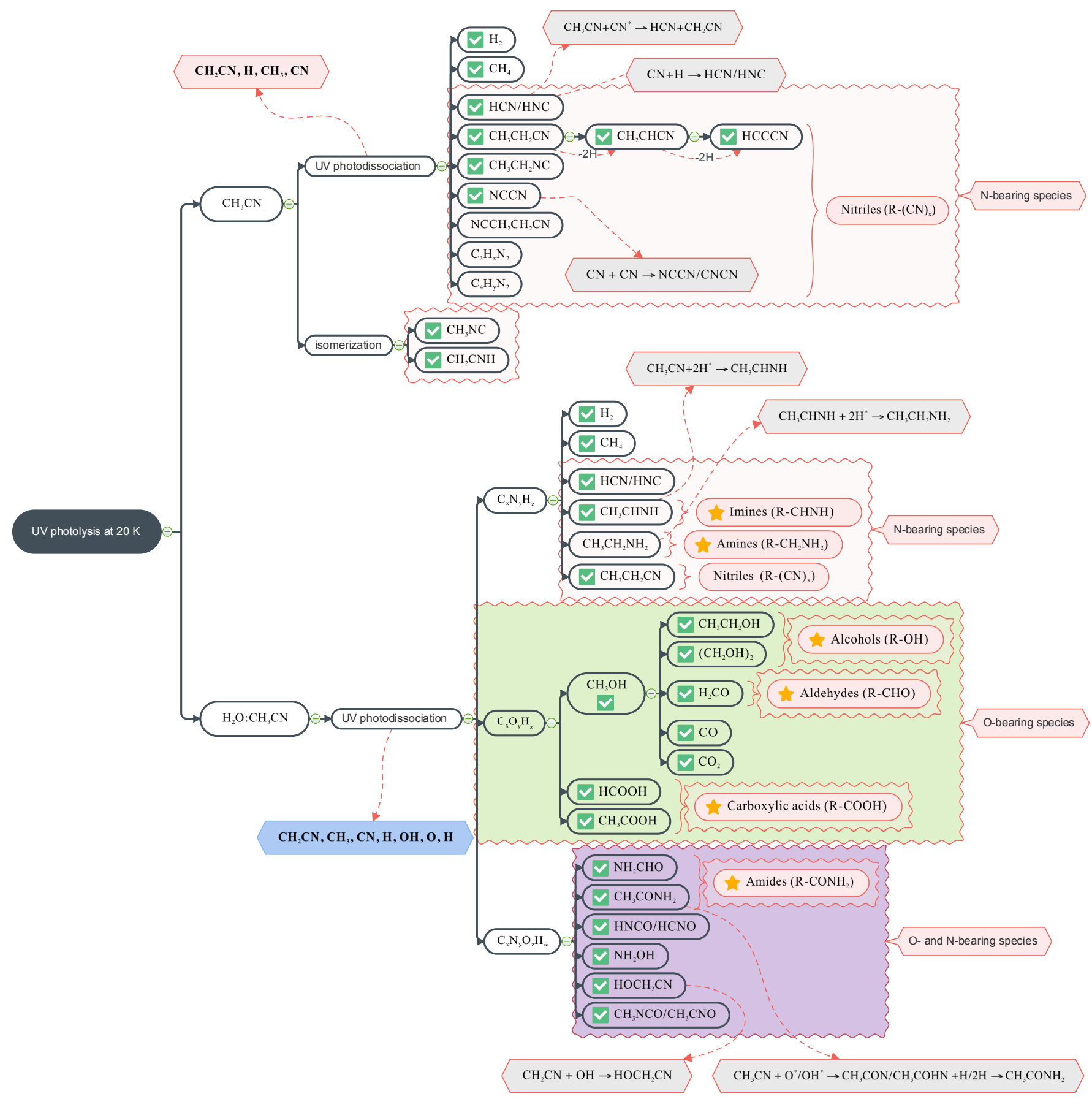

Fig. 9. Overview of products of $\mathrm{UV}$ photolysis of $\mathrm{CH}_{3} \mathrm{CN}$ and $\mathrm{H}_{2} \mathrm{O}: \mathrm{CH}_{3} \mathrm{CN}(20: 1)$ ices at $20 \mathrm{~K}$. For the clarity of the figure, radicals and subgroups of photoproducts in the ice are separated by colored rectangular frames. Groups of molecules uniquely produced in the ice mixtures with water are marked by a yellow star. The species marked with a check mark have been detected in the ISM. The formation pathways included in the figure are based on the interpretation of our experimental data and a discussion in Sect. 4.

Jones et al. 2011; Ioppolo et al. 2021). To fully benefit from the work presented here, modeling will be needed to set the significance of $\mathrm{CH}_{3} \mathrm{CN}$ ice chemistry into the larger astrochemical context. To this end, it also will be important to better understand how $\mathrm{CH}_{3} \mathrm{CN}$ forms.

It should be noted that ices in the ISM normally do not exist in their pure form. Typically, ices comprise of a polar waterrich layer, mixed with, for example, $\mathrm{NH}_{3}, \mathrm{CH}_{4}$, and $\mathrm{CO}_{2}$, and an a-polar $\mathrm{CO}$ coating that contains reaction products of hydrogenation, such as $\mathrm{CH}_{3} \mathrm{OH}$ (Boogert et al. 2015; Linnartz et al. 2015).
Here, we experimentally investigate a scenario of $\mathrm{CH}_{3} \mathrm{CN}$ formation in the water-rich ice, as it is the most abundant interstellar ice constituent. In the laboratory, an ice analogue $\mathrm{H}_{2} \mathrm{O}: \mathrm{CH}_{3} \mathrm{CN}$ (20:1) allows us to study the radical interactions of acetonitrile and water upon UV dissociation. In a real ice with more components, the observed level of chemical complexity will be exceed beyond the network in Fig. 5.

There are different astronomical environments where the processes described here may be at play. In dense dark clouds, it is generally assumed that solid state astrochemical processes 
are driven by atom addition reactions (Linnartz et al. 2015). It is here that smaller molecules like $\mathrm{H}_{2} \mathrm{O}, \mathrm{NH}_{3}$, and $\mathrm{HNCO}$ or $\mathrm{CH}_{4}$ form, as well as larger species, including glycerol (Fedoseev et al. 2017). UV-induced chemistry is considered to be less important (Chuang et al. 2017), but cannot be excluded. In dark clouds, ices are exposed to cosmic ray-induced UV irradiation. In the more translucent cloud areas, as well as in protoplanetary disks, UV-induced chemistry takes over. During the star formation cycle, these energetically processed ices are eventually desorbed, allowing for the detection of COMs in the gas phase. Hence, it is interesting to compare the products detected during the UV photolysis of the $\mathrm{CH}_{3} \mathrm{CN}$ and $\mathrm{H}_{2} \mathrm{O}: \mathrm{CH}_{3} \mathrm{CN}$ (20:1) ices with astrochemical observations and models.

After an exposure of a pure $\mathrm{CH}_{3} \mathrm{CN}$ ice to a photon fluence of $8.9 \times 10^{17}$ photons $\mathrm{cm}^{-2}, 25 \%$ of $\mathrm{CH}_{3} \mathrm{CN}$ molecules are converted to other species. The products that are larger than the parent species, supplying the N-bearing COM reservoir, make up for $25 \%$ of the lost parent molecules. The same analysis was performed for the water-dominated mixture (20:1). In particular, $25 \%$ of water molecules were depleted while $85 \%$ of acetonitrile molecules were consumed (see Appendix B). This demonstrates that water effectively prevents the recombination of $\mathrm{CH}_{3} \mathrm{CN}$ and enhances its photoconversion by providing reactive $\mathrm{O}, \mathrm{OH}$, and $\mathrm{H}$ radicals. Thus, on the dark cloud time scales, a high conversion rate of $\mathrm{CH}_{3} \mathrm{CN}$ into the photoproducts can be expected.

The photolysis of pure $\mathrm{CH}_{3} \mathrm{CN}$ ice leads to isomerization (Hudson \& Moore 2004) or formation of other nitrile based species, as demonstrated in this study. HCN is the most abundant product of photolysis, but many other species are formed, including: $\mathrm{CH}_{3} \mathrm{CH}_{2} \mathrm{CN}$ and $\mathrm{NCCH}_{2} \mathrm{CH}_{2} \mathrm{CN}$. The types of reactions leading to this complexity are radical-radical recombinations (e.g. $\mathrm{CH}_{3}+\mathrm{CH}_{2} \mathrm{CN} \rightarrow \mathrm{CH}_{3} \mathrm{CH}_{2} \mathrm{CN}$ ), radicalmolecule interactions (e.g. $\mathrm{CH}_{3} \mathrm{CN}+\mathrm{CN} \rightarrow \mathrm{HCN}+\mathrm{CH}_{2} \mathrm{CN}$ ) and (de)hydrogenation reactions (e.g., $\mathrm{CH}_{3} \mathrm{CH}_{2} \mathrm{CN}-2 \mathrm{H} \rightarrow$ $\mathrm{CH}_{2} \mathrm{CHCN}$ and $\mathrm{CH}_{3} \mathrm{CN}+2 \mathrm{H} \rightarrow \mathrm{CH}_{3} \mathrm{CHNH}$ ). Specifically for $\mathrm{HCN}$, it is clear that radical-radical interactions alone are not sufficient to account for its formation yield.

The chemical complexity resulting from the pure $\mathrm{CH}_{3} \mathrm{CN}$ photolysis is shown in the upper part of Fig. 9. All photoproducts, except for $\mathrm{NCCN}$ and $\mathrm{NCCH}_{2} \mathrm{CH}_{2} \mathrm{CN}$, have been observed in the ISM. However, the presence of NCCN in the ISM is implied by detections of two closely related species: a metastable isomer $\mathrm{CNCN}$ and the protonated form of cyanogen, $\mathrm{NCCNH}^{+}$ (Agúndez et al. 2015, 2018). Both of the species are detected in dense clouds L483 and TMC-1. The known formation mechanism of NCCN includes an exothermic gas phase pathway via a neutral-neutral reaction: $\mathrm{CN}+\mathrm{HCN} \rightarrow \mathrm{NCCN}+\mathrm{H}$ (Petrie et al. 2003). Alternatively, it is suggested that it might be also formed on dust grains through a recombination of two $\mathrm{CN}$ radicals. This is indeed the case in our experiments. It is important to note that the formation of $\mathrm{NCCN} / \mathrm{CNCN}$, as well as $\mathrm{NCCH}_{2} \mathrm{CH}_{2} \mathrm{CN}$, is only visible for the pure $\mathrm{CH}_{3} \mathrm{CN}$ ice photolysis; thus, both species could be used as tracers of an ice that is rich in $\mathrm{CN}$.

In a more realistic case, the $\mathrm{CH}_{3} \mathrm{CN}$ is diluted in a $\mathrm{H}_{2} \mathrm{O}$ ice and this mixture yields significantly more complexity (shown in the lower part of Fig. 9). Even though it is not possible to assign all observed mass peaks unambiguously to specific carrier molecules, the mass spectra reveal trends that can be connected to chemical families. It is clear that a diverse number of larger $\mathrm{N}$-containing COMs is formed upon UV irradiation of $\mathrm{H}_{2} \mathrm{O}: \mathrm{CH}_{3} \mathrm{CN}$ ice. In the presence of water, the $\mathrm{C} \equiv \mathrm{N}$ bond of acetonitrile can be hydrogenated, leading to the formation of imines and amines. In the study by Loomis et al. (2013), $\mathrm{CH}_{3} \mathrm{CHNH}$ was observed towards Sgr B2(N) and now its formation pathway is demonstrated to be possible via hydrogenation of $\mathrm{CH}_{3} \mathrm{CN}$. The hydrogenation process continues until $\mathrm{CH}_{3} \mathrm{CH}_{2} \mathrm{NH}_{2}$ is formed, which has the highest abundance towards the end of the UV photolysis. However, this molecule is yet to be detected in the ISM.

The reactivity of $\mathrm{O}$ and $\mathrm{OH}$ radicals with the $\mathrm{C} \equiv \mathrm{N}$ bond provides a chemical link between the O- and N-bearing chemical networks. Specifically, formation of amides is suggested to proceed via the $\mathrm{O} / \mathrm{OH}$ radical interacting with the parent nitrile molecule, which, when followed by hydrogenation reaction, yields $\mathrm{CH}_{3} \mathrm{CONH}_{2}$. Other formed $\mathrm{N}$ - and O-bearing species include $\mathrm{HNCO} / \mathrm{HCNO}, \mathrm{NH}_{2} \mathrm{OH}, \mathrm{CH}_{3} \mathrm{NCO}$ and $\mathrm{HOCH}_{2} \mathrm{CN}$. All of these molecules, except for an $\mathrm{CH}_{3} \mathrm{NCO}$ isomer, namely, $\mathrm{CH}_{3} \mathrm{CNO}$, have been observed in the ISM. The formation mechanism of $\mathrm{HOCH}_{2} \mathrm{CN}$, observed in IRAS-16293B (Zeng et al. 2019) and in Serpens SMM1-a (Ligterink et al. 2020a), is suggested to have a solid state route. In our experiments, it most likely proceeds via $\mathrm{OH}+\mathrm{CH}_{2} \mathrm{CN} \rightarrow \mathrm{HOCH}_{2} \mathrm{CN}$, as both of these radicals are immediately available to react. Alternatively, this product might be formed through reactions involving $\mathrm{H}_{2} \mathrm{CO}$, $\mathrm{NH}_{3}$ with $\mathrm{CN}^{-}$(Danger et al. 2012).

\section{Conclusions}

In conclusion, the UV photolysis of pure $\mathrm{CH}_{3} \mathrm{CN}$ ice yields larger nitriles including NCCN/CNCN, $\mathrm{CH}_{3} \mathrm{CH}_{2} \mathrm{CN}$ and $\mathrm{NCCH}_{2} \mathrm{CH}_{2} \mathrm{CN}$. In addition, we demonstrate here that the $\mathrm{H}$ atom abstraction reactions are an efficient formation pathway of $\mathrm{HCN}$. The UV photolysis of an astronomically relevant $\mathrm{H}_{2} \mathrm{O}: \mathrm{CH}_{3} \mathrm{CN}$ ice at $20 \mathrm{~K}$, leads to the formation of larger (at least up to 6-7 C/N/O-containing) molecules with the functional groups of: imines, amines, amides, large nitriles, carboxylic acids, and alcohols. Photodissociation products of $\mathrm{H}_{2} \mathrm{O}$ play a key role in this chemical network. Hydrogenation of the $\mathrm{C} \equiv \mathrm{N}$ bond leads to formation of imines and amines, whereas the interaction of $\mathrm{O}$ - and $\mathrm{OH}$ with the $\mathrm{C} \equiv \mathrm{N}$ bond results in formation of amides. The identification of photoproducts (see Fig. 9) provides a tool to link astronomical observations of (N- and O-bearing) COMs to the underlying solid state processes in which these are formed. In this study, it is shown that $\mathrm{CH}_{3} \mathrm{CN}$ can play a central role in the chemical network that ultimately results in a further increase of molecular complexity in space. Many of these species already have been identified in recent studies (van Gelder et al. 2020; Ligterink et al. 2020b; Nazarri et al., in prep.), while other species that have not been identified yet may be well present in the ISM, following the work presented here.

Acknowledgements. M.B. and H.L. acknowledge the European Union (EU) and Horizon 2020 funding awarded under the Marie Skłodowska-Curie action to the EUROPAH consortium (grant number 722346) as well as NOVA 5 funding. Additional funding has been realized through a NWO-VICI grant. This work has been supported by the Danish National Research Foundation through the Center of Excellence "InterCat" (Grant agreement no.: DNRF150). We thank N. F. W. Ligterink, A. G. G. M. Tielens, J. Terwischa van Scheltinga, J. Bouwman and T. Lamberts for helpful discussions.

\section{References}

Abdulgalil, A. G. M., Marchione, D., Thrower, J. D., et al. 2013, Phil. Trans. R. Soc. A, 371, 20110586

Agúndez, M., Cernicharo, J., de Vicente, P., et al. 2015, A\&A, 579, L10

Agúndez, M., Marcelino, N., \& Cernicharo, J. 2018, ApJ, 861, L22

Andersson, S., \& van Dishoeck, E. F. 2008, A\&A, 491, 907

Baratta, G. A., \& Palumbo, M. E. 1998, J. Opt. Soc. Am. A, 15, 3076

Belloche, A., Garrod, R. T., Müller, H. S. P., et al. 2009, A\&A, 499, 215

Belloche, A., Menten, K. M., Comito, C., et al. 2008, A\&A, 482, 179 


\section{Bulak et al.: UV photolysis of $\mathrm{CH}_{3} \mathrm{CN}$ and $\mathrm{H}_{2} \mathrm{O}: \mathrm{CH}_{3} \mathrm{CN}$ ices}

Belloche, A., Meshcheryakov, A. A., Garrod, R. T., et al. 2017, A\&A, 601, A49 Belloche, A., Garrod, R. T., Müller, H. S. P., et al. 2019, A\&A, 628, A10

Bergner, J. B., Öberg, K. I., Garrod, R. T., \& Graninger, D. M. 2017, ApJ, 841, 120

Bergner, J. B., Guzmán, V. G., Öberg, K. I., Loomis, R. A., \& Pegues, J. 2018 ApJ, 857, 69

Bernstein, M. P., Dworkin, J. P., Sandford, S. A., Cooper, G. W., \& Allamandola, L. J. 2002, Nature, 416, 401

Bisschop, S. E., Jørgensen, J. K., van Dishoeck, E. F., \& de Wachter, E. B. M. 2007, A\&A, 465, 913

Bizzocchi, L., Prudenzano, D., Rivilla, V. M., et al. 2020, A\&A, 640, A98

Boogert, A. C. A., Gerakines, P. A., \& Whittet, D. C. B. 2015, ARA\&A, 53, 541

Borget, F., Müller, S., Grote, D., et al. 2017, A\&A, 598, A22

Bulak, M., Paardekooper, D. M., Fedoseev, G., \& Linnartz, H. 2020, A\&A, 636, A32

Calcutt, H., Jørgensen, J. K., Müller, H. S. P., et al. 2018, A\&A, 616, A90

Castellanos, P., Candian, A., Zhen, J., Linnartz, H., \& Tielens, A. G. G. M. 2018, A\&A, 616, A166

Chuang, K. J., Fedoseev, G., Ioppolo, S., van Dishoeck, E. F., \& Linnartz, H. 2016, MNRAS, 455, 1702

Chuang, K. J., Fedoseev, G., Qasim, D., et al. 2017, MNRAS, 467, 2552

Congiu, E., Chaabouni, H., Laffon, C., et al. 2012, J. Chem. Phys., 137, 054713

Cordiner, M. A., Palmer, M. Y., Nixon, C. A., et al. 2015, ApJ, 800, L14

Crowley, J. N., \& Sodeau, J. R. 1989, J. Phys. Chem., 93, 3100

Danger, G., Bossa, J. B., de Marcellus, P., et al. 2011, A\&A, 525, A30

Danger, G., Duvernay, F., Theulé, P., Borget, F., \& Chiavassa, T. 2012, ApJ, 756,11

Darwent, B. d. 1970, Nat. Stand Ref. Data System - Natl. Bur. Stand, U.S. Gov., NSRDS-NBS 31

Fedoseev, G., Ioppolo, S., Lamberts, T., et al. 2012, J. Chem. Phys., 137, 054714

Fedoseev, G., Chuang, K. J., van Dishoeck, E. F., Ioppolo, S., \& Linnartz, H. 2016, MNRAS, 460, 4297

Fedoseev, G., Chuang, K. J., Ioppolo, S., et al. 2017, ApJ, 842, 52

Fourikis, N., Takagi, K., \& Morimoto, M. 1974, ApJ, 191, L139

Fourré, I., Matz, O., Ellinger, Y., \& Guillemin, J. C. 2020, A\&A, 639, A16

Fuchs, G. W., Cuppen, H. M., Ioppolo, S., et al. 2009, A\&A, 505, 629

Garrod, R. T., \& Herbst, E. 2006, A\&A, 457, 927

Garrod, R. T., Widicus Weaver, S. L., \& Herbst, E. 2008, ApJ, 682, 283

Gerakines, P. A., Moore, M. H., \& Hudson, R. L. 2004, Icarus, 170, 202

Goesmann, F., Rosenbauer, H., Bredehöft, J. H., et al. 2015, Science, 349, 2.689

Gratier, P., Pety, J., Guzmán, V., et al. 2013, A\&A, 557, A101

Gudipati, M. S., \& Yang, R. 2012, ApJ, 756, L24

Halfen, D. T., Ilyushin, V. V., \& Ziurys, L. M. 2015, ApJ, 812, L5

Hollis, J. M., Lovas, F. J., Remijan, A. J., et al. 2006, ApJ, 643, L25

Hudson, R. L., \& Moore, M. H. 2004, Icarus, 172, 466

Hudson, R. L., Moore, M. H., Dworkin, J. P., Martin, M. P., \& Pozun, Z. D. 2008, Astrobiology, 8, 771

Ioppolo, S., Fedoseev, G., Minissale, M., et al. 2014, Phys. Chem. Chem. Phys., 16,8270

Ioppolo, S., Fedoseev, G., Chuang, K. J., et al. 2021, Nat. Astron., in press

Islam, F., Baratta, G. A., \& Palumbo, M. E. 2014, A\&A, 561, A73

Jin, M., \& Garrod, R. T. 2020, ApJS, 249, 26

Jones, B. M., Bennett, C. J., \& Kaiser, R. I. 2011, ApJ, 734, 78

Kanda, K., Nagata, T., \& Ibuki, T. 1999, Chem. Phys., 243, 89

Kim, Y. K., Irikura, K. K., Rudd, M. E., \& Ali, M. A. 2014, Electron-Impact Ionization Cross Section for Ionization and Excitation Database (version 3.0)

Lattelais, M., Pauzat, F., Ellinger, Y., \& Ceccarelli, C. 2010, A\&A, 519, A30

Lee, J.-E., Lee, S., Baek, G., et al. 2019, Nat. Astron., 3, 314

Ligterink, N. F. W., Coutens, A., Kofman, V., et al. 2017, MNRAS, 469, 2219
Ligterink, N. F. W., Terwisscha van Scheltinga, J., Taquet, V., et al. 2018, MNRAS, 480, 3628

Ligterink, N. F. W., Ahmadi, A., Coutens, A., et al. 2020a, A\&A, accepted Ligterink, N. F. W., El-Abd, S. J., Brogan, C. L., et al. 2020b, ApJ, 901, 37

Linnartz, H., Ioppolo, S., \& Fedoseev, G. 2015, Int. Rev. Phys. Chem., 34, 205

Liszt, H., Gerin, M., Beasley, A., \& Pety, J. 2018, ApJ, 856, 151

Loomis, R. A., Zaleski, D. P., Steber, A. L., et al. 2013, ApJ, 765, L9

Loomis, R. A., Cleeves, L. I., Öberg, K. I., et al. 2018, ApJ, 859, 131

Mackay, D. D. S. 1999, MNRAS, 304, 61

McGuire, B. A. 2018, ApJS, 239, 17

Mu noz Caro, G. M., Dartois, E., Boduch, P., et al. 2014, A\&A, 566, A93

Mumma, M. J., \& Charnley, S. B. 2011, ARA\&A, 49, 471

Nguyen, T., Fourré, I., Favre, C., et al. 2019, A\&A, 628, A15

Öberg, K. I., Garrod, R. T., van Dishoeck, E. F., \& Linnartz, H. 2009, A\&A, 504,891

Öberg, K. I., van Dishoeck, E. F., Linnartz, H., \& Andersson, S. 2010, ApJ, 718,832

Öberg, K. I., Furuya, K., Loomis, R., et al. 2015, ApJ, 810, 112

Paardekooper, D. M., Bossa, J.-B., Isokoski, K., \& Linnartz, H. 2014, Rev. Sci. Instrum.

Paardekooper, D. M., Bossa, J. B., \& Linnartz, H. 2016a, A\&A, 592, A67

Paardekooper, D. M., Fedoseev, G., Riedo, A., \& Linnartz, H. 2016b, A\&A, 596, A72

Pandya, S. H., Shelat, F. A., Joshipura, K. N., \& Vaishnav, B. G. 2012, Int. J. Mass Spectr., 323-324, 28

Petrie, S., Millar, T. J., \& Markwick, A. J. 2003, MNRAS, 341, 609

Purcell, C. R., Balasubramanyam, R., Burton, M. G., et al. 2006, MNRAS, 367, 553

Qasim, D., Fedoseev, G., Chuang, K. J., et al. 2020, Nat. Astron., 4, 781

Raunier, S., Chiavassa, T., Marinelli, F., \& Aycard, J.-P. 2004, Chem. Phys., 302,259

Ribeiro, F. d. A., Almeida, G. C., Wolff, W., et al. 2020, MNRAS, 492, 2140

Rivilla, V. M., Martín-Pintado, J., Jiménez-Serra, I., et al. 2020, ApJ, 899, L28

Ruscic, B., Pinzon, R. E., Morton, M. L., et al. 2004, J. Phys. Chem. A, 108, 9979

Schwell, M., Jochims, H.-W., Baumgärtel, H., \& Leach, S. 2008, Chem. Phys., 344,164

Shannon, R. J., Blitz, M. A., Goddard, A., \& Heard, D. E. 2013, Nat. Chem., 5,745

Shen, C. J., Greenberg, J. M., Schutte, W. A., \& van Dishoeck, E. F. 2004, A\&A, 415, 203

Sleiman, C., González, S., Klippenstein, S. J., et al. 2016, Phys. Chem. Chem. Phys., 18, 15118

Snyder, L. E., \& Bhul, D. 1971, BAAS, 3, 388

Solomon, P. M., Jefferts, K. B., Penzias, A. A., \& Wilson, R. W. 1971, ApJ, 168, L107

Theule, P., Borget, F., Mispelaer, F., et al. 2011, A\&A, 534, A64

van Dishoeck, E. F. 2014, Faraday Discuss., 168, 9

van Gelder, M. L., Tabone, B., Tychoniec, Ł., et al. 2020, A\&A, 639, A87

van Harrevelt, R., \& van Hemert, M. C. 2008, J. Phys. Chem. A, 112, 3002

Vigren, E., Kamińska, M., Hamberg, M., et al. 2008, Phys. Chem. Chem. Phys., 10,4014

Walsh, C., Millar, T. J., Nomura, H., et al. 2014, A\&A, 563, A33

Watanabe, N., Shiraki, T., \& Kouchi, A. 2003, ApJ, 588, L121

Willacy, K., Williams, D. A., \& Minh, Y. C. 1993, MNRAS, 263, L40

Woodney, L. M., A'Hearn, M. F., Schleicher, D. G., et al. 2002, Icarus, 157, 193

Zeng, S., Jiménez-Serra, I., Rivilla, V. M., et al. 2018, MNRAS, 478, 2962

Zeng, S., Quénard, D., Jiménez-Serra, I., et al. 2019, MNRAS, 484, L43

Zhou, W., Wilkinson, L., Lee, J. W. L., Heathcote, D., \& Vallance, C. 2019, Mol. Phys., 117, 3066 


\section{Appendix A: Identification of photoproducts via thermal desorption}

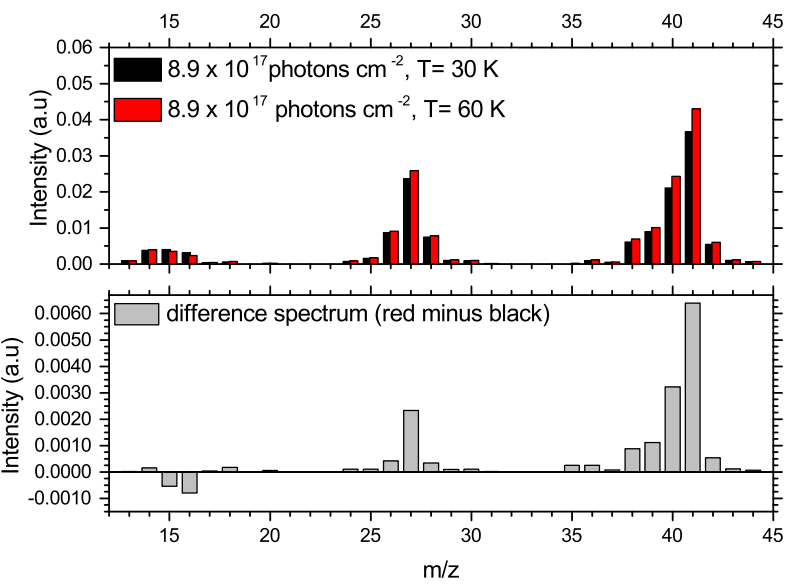

Fig. A.1. Top panel: integrated LDPI TOF-MS signals for an UVirradiated $\mathrm{CH}_{3} \mathrm{CN}$ ice at $20 \mathrm{~K}$ that is subsequently heated to a temperature of $30 \mathrm{~K}$ (black sticks) and $60 \mathrm{~K}$ (red sticks). The identification of $\mathrm{CH}_{4}$ formation in the ice becomes visible when subtracting the 60 and $30 \mathrm{~K}$ data as $\mathrm{CH}_{4}$ thermally desorbs around $40 \mathrm{~K}$. This is shown in the lower panel; at $m / z=15$ and 16 this results in a negative value.

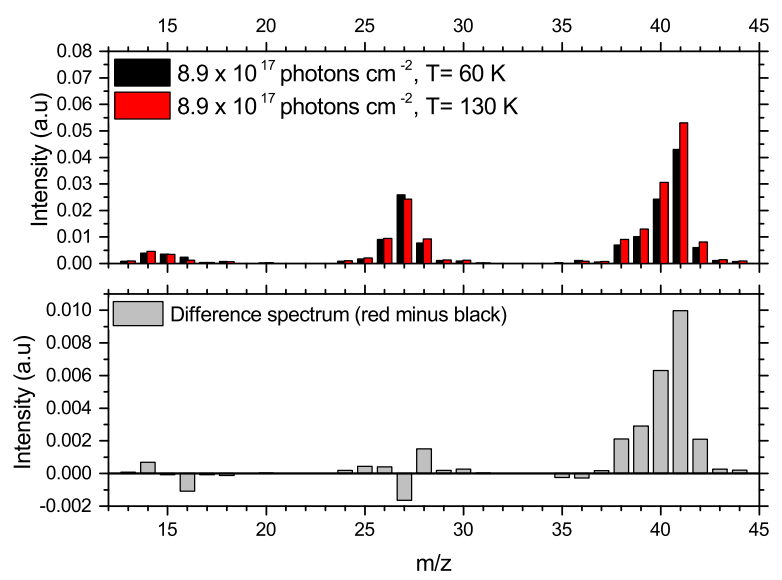

Fig. A.2. Top panel: integrated LDPI TOF-MS signals for an UVirradiated $\mathrm{CH}_{3} \mathrm{CN}$ ice at $20 \mathrm{~K}$ that is subsequently heated to a temperature of $60 \mathrm{~K}$ (black sticks) and $130 \mathrm{~K}$ (red sticks). The identification of $\mathrm{HCN}$ formation in the ice becomes visible when subtracting the 130 and $60 \mathrm{~K}$ data as HCN thermally desorbs around $120 \mathrm{~K}$. This is shown in the lower panel; at $m / z=27$ this results in a negative value. In addition, thermal desorption of remaining $\mathrm{CH}_{4}$ trapped in the ice is observed at $m / z=16$.

\section{Appendix B: Quantified impact of water on the UV photochemistry in solid state}

In an attempt to quantitatively demonstrate the influence of the amount of water on formation and destruction of molecules, the abundance of analyzed species is plotted for 20:1 and 1:1 $\mathrm{H}_{2} \mathrm{O}: \mathrm{CH}_{3} \mathrm{CN}$ mixing ratios and compared to pure $\mathrm{CH}_{3} \mathrm{CN}$ ice. Figure B.1. shows the consumption of $\mathrm{CH}_{3} \mathrm{CN}$ in the water ices with 10-20\% left towards the end of the UV photolysis, while for the pure ice, $80 \%$ of $\mathrm{CH}_{3} \mathrm{CN}$ remains. This difference must be linked to reactivity of $\mathrm{H}_{2} \mathrm{O}$ fragments $(\mathrm{H}$ and $\mathrm{OH})$ formed

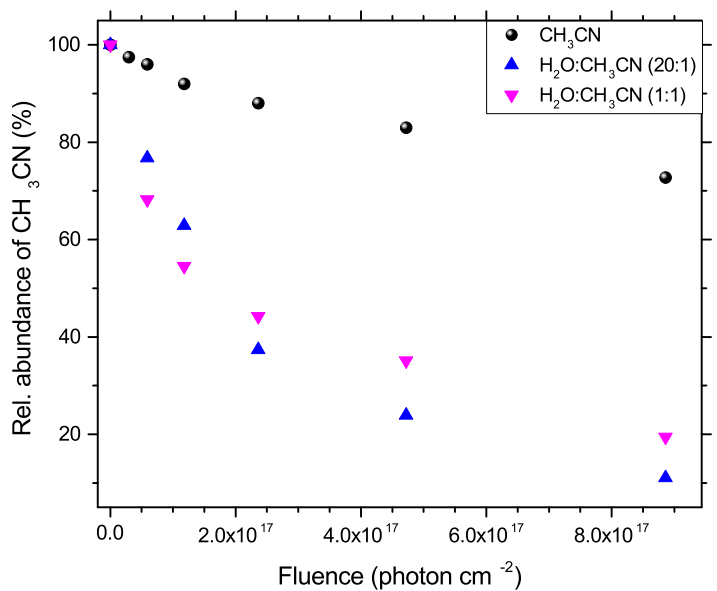

Fig. B.1. Consumption of $\mathrm{CH}_{3} \mathrm{CN}$ during $\mathrm{UV}$ photolysis of pure $\mathrm{CH}_{3} \mathrm{CN}$ and mixed ices $\left(\mathrm{H}_{2} \mathrm{O}: \mathrm{CH}_{3} \mathrm{CN}\right)$.
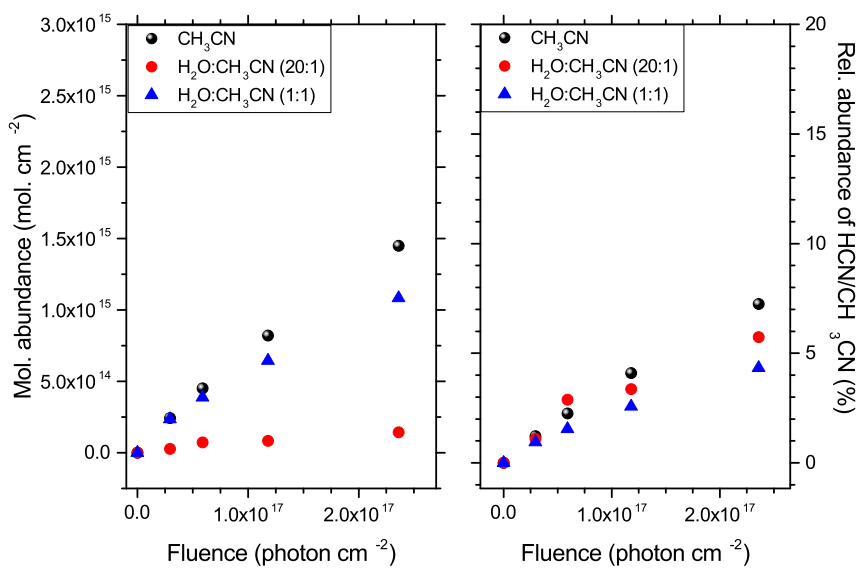

Fig. B.2. Absolute (left panel) and relative (right panel) abundance of the formed $\mathrm{HCN}(\mathrm{m} / \mathrm{z}=27)$ as function of UV fluence for the pure $\mathrm{CH}_{3} \mathrm{CN}$ and mixed ices $\left(\mathrm{H}_{2} \mathrm{O}: \mathrm{CH}_{3} \mathrm{CN}\right)$ irradiation experiments.

upon UV irradiation. To quantify this effect, a dedicated study of multiple ratios of initial ice compositions is required.

The formation of photoproducts in the $\mathrm{H}_{2} \mathrm{O}: \mathrm{CH}_{3} \mathrm{CN}$ mixed ices has been measured for $\mathrm{HCN}$ and $\mathrm{CH}_{3} \mathrm{OH}$. Quantitative analysis of HCN formation is shown in Fig. B.2. for three initial ice mixtures, based on $m / z=27$. At least at the early stage of photolysis, this mass peak can be associated with the molecular ion of $\mathrm{HCN}$. The absolute yield of $\mathrm{HCN}$ (in $\mathrm{mol} \mathrm{cm} \mathrm{cm}^{-2}$ ) increases with an increased precursor abundance of $\mathrm{CH}_{3} \mathrm{CN}$ (left panel). The formation efficiency relative to the initial $\mathrm{CH}_{3} \mathrm{CN}$ abundance $\left(\mathrm{HCN} / \mathrm{CH}_{3} \mathrm{CN}\right.$ ) remains rather similar for all studied ices (right panel), consistent with a non-detectable influence of water and a clear chemical link between $\mathrm{HCN}$ and $\mathrm{CH}_{3} \mathrm{CN}$.

Figure B.3. demonstrates the formation of $\mathrm{CH}_{3} \mathrm{OH}$ (based on peak $m / z=32)$ in two studied mixtures $(1: 1$ and $20: 1)$. The absolute yield of $\mathrm{CH}_{3} \mathrm{OH}$ (left panel) in the 1:1 mixture is twice as high, compared to the 20:1 mixture, due to the greater amount of $\mathrm{CH}_{3} \mathrm{CN}$ available as a precursor. The formation efficiency relative to the initial $\mathrm{CH}_{3} \mathrm{CN}$ abundance $\left(\mathrm{CH}_{3} \mathrm{OH} / \mathrm{CH}_{3} \mathrm{CN}\right)$ data (right panel) is consistent with a higher efficiency of $\mathrm{CH}_{3} \mathrm{OH}$ formation in the water dominated (20:1) ice mixture. 
M. Bulak et al.: UV photolysis of $\mathrm{CH}_{3} \mathrm{CN}$ and $\mathrm{H}_{2} \mathrm{O}: \mathrm{CH}_{3} \mathrm{CN}$ ices

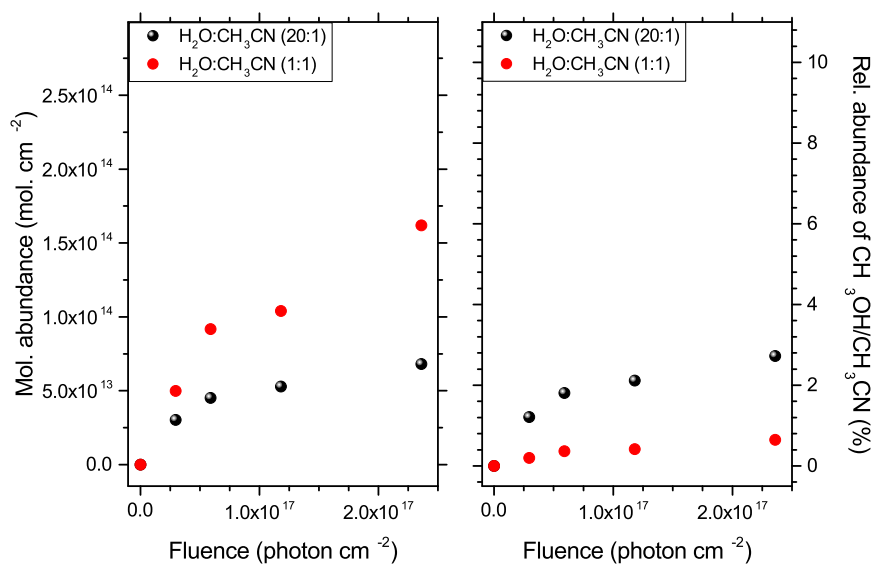

Fig. B.3. Absolute (left panel) and relative (right panel) abundance of the formed $\mathrm{CH}_{3} \mathrm{OH}(\mathrm{m} / \mathrm{z}=32)$ as function of UV fluence for the mixed ices $\left(\mathrm{H}_{2} \mathrm{O}: \mathrm{CH}_{3} \mathrm{CN}\right)$ irradiation experiments. 